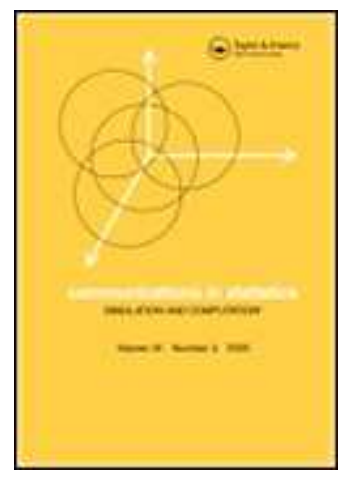

\title{
On joint determination of the number of states and the number of variables in Markov-switching models: A Monte Carlo study
}

\begin{tabular}{|r|l|}
\hline Journal: & Communications in Statistics - Simulation and Computation \\
\hline Manuscript ID: & draft \\
\hline Manuscript Type: & Original Paper \\
\hline Date Submitted by the \\
Author:
\end{tabular}

\section{S) ScholaroNE \\ Manuscript Central}




\title{
On joint determination of the number of states and the number of variables in Markov-switching models: A Monte Carlo study
}

\author{
Thatphong Awirothananon \\ Griffith Business School \\ Griffith University
}

\author{
Wai-Kong (Adrian) Cheung* \\ Griffith Business School \\ Griffith University
}

\begin{abstract}
In this paper, we examine the performance of two newly developed procedures that jointly select the number of states and variables in Markov-switching models by means of Monte Carlo simulations. They are Smith, Naik and Tsai (2006) and Psaradakis and Spagnolo (2006), respectively. The former develops Markov switching criterion (MSC) designed specifically for Markov-switching models, while the latter recommends the use of standard complexity-penalised information criteria (BIC, HQC, and AIC) in joint determination of the state dimension and the autoregressive order of Markov-switching models. The Monte Carlo evidence shows that BIC outperforms MSC while MSC and HQC are preferable over AIC.
\end{abstract}

JEL Classifications: C01; C13; C15; C50

Keywords: Information criteria; Markov-switching model; Monte Carlo

\footnotetext{
* Co-responding author; E-mail address: a.cheung@griffith.edu.au. Telephone number: 61-7-3735 7644. Address: Department of Accounting, Finance, and Economics, Griffith Business School, Griffith University, Nathan, Queensland 4111, Australia.
} 


\section{Introduction}

Markov-switching models have become increasingly popular in the modelling of economic or financial variables since the publication of Hamilton's (1989) influential paper. As shown in Timmermann (2000), these models are flexible enough to capture some well-known characteristics of economic or financial variables such as serial correlation, asymmetry, and fat tail behaviour.

To estimate Markov-switching models, a key problem that arises in applications is that the number of states is often unknown a priori. This leads to a breakdown of regularity conditions that prevents the use of the likelihood ratio test in the traditional framework of standard maximum likelihood theory. Another problem is that the order of autoregressive parameters is also unknown if the true model is believed to be a Markov-switching autoregressive model. The standard practice in applied econometrics is that these two problems are dealt with in a two-step procedure. Step One selects the order of autoregressive parameters using some kind of information criterion. Then Step Two determines the number of states accordingly. This procedure is problematic in the following sense: First, the efficacy of Step Two hinges upon the validity of the result of Step One. Second, in principle, one may start off with any one of the two problems first and then solve the remaining one later. But the result could be very different. For example, one may find the optimal autoregressive order being two in Step One and then the number of states being two in Step Two; if the procedure is reverse, it is likely that the number of states is two while the optimal autoregressive order is one. In this situation, one needs additional information as to which results one may count on.

Recently, Psaradakis and Spagnolo (2006) (hereafter called PS (2006)) propose a new procedure that gets around the limitations of standard practice. The new procedure combines two steps to one single step where an information criterion is used consistently in joint determination of the number of states and the autoregressive order. Based on simulation evidence, they show that complexitypenalised likelihood criteria like AIC, BIC, and HQC can accurately identify the correct model 
The purpose of this paper is to compare whether MSC is better than standard information criteria such as AIC, BIC, and HQC using simulation studies. In particular, we deal with the following issues:

1. PS (2006) are concerned with Markov-switching autoregressive models only while SNT (2006)'s MSC is derived and based on Markov-switching static models. It is interesting to see whether PS (2006)'s procedure also works well in Markov-switching static model or not.

2. As far as the usefulness of AIC is concerned, there is apparently inconsistent result between SNT (2006) and PS (2006). SNT (2006) argue and present simulation evidence that AIC is misleading in the sense that it retains too many states and variables than the true model, resulting in reduction in accuracy of estimated parameters and precision of model forecasts. However, the results in PS (2006) reveal that AIC is the most successful criterion in terms of the

\footnotetext{
${ }^{1}$ In fact, Smith, Naik and Tsai (2006) made the following remark on page 560. "We encourage further research to investigate such comparisons using the proposed MSC."
} 
frequency of correct model identification, followed closely by BIC and HQC (p. 761). This paper sheds light on resolving this apparent conflict.

3. The primary focus of SNT (2006) is on the absolute performance of MSC even though it also discusses briefly the over-selection problem of using AIC. When it comes to applications, it is important to know about the relative performance of MSC over other standard information criteria. This paper aims to provide direct evidence on this issue.

The simulation results suggest that BIC performs well in Markov-switching models, regardless of whether the model is static or autoregressive. Consistent with SNT (2006), we find evidence that AIC retains too many states and variables than the true model and that MSC outperforms AIC in identifying the correct model structure. To our surprise, BIC is the best criterion in terms of the frequency of correct model identification while AIC is the least successful one. This result is in sharp contrast with that of PS (2006) and provides new evidence on the usefulness of BIC and MSC.

The reminder of the paper is organised as follows. Section 2 presents the class of Markov-switching models under consideration and discusses MSC and other standard information criteria to be examined. Section 3 presents the set up of Monte Carlo studies and their results. Section 4 concludes the paper.

\section{Models and assumptions}

This paper considers the Markov-switching models of the following form: ${ }^{2}$

$$
y_{t}=v^{\left(s_{t}\right)}+\sum_{l=1}^{p} A_{l}^{\left(s_{t}\right)} y_{t-l}+\sigma^{\left(s_{t}\right)} e_{t},
$$

where $e_{t}$ is independent and identically distributed random variables such that $\mathrm{E}\left(e_{t}\right)=0$ and

\footnotetext{
${ }^{2}$ Autoregressive model is used here for illustration purpose only. To get the equation for static model, just replace the set of lagged $y_{t}$ variables by the same number of exogenous variables, $x_{t}$.
} 
$s_{t}$ are unobservable random variables that take values in the finite set $\{1,2, \ldots, r\}$ and are independent of $e_{t}$.

The random variables $s_{t}$ (hereafter referred to as regime variables) are assumed to be a temporally homogeneous first-order Markov chain on $\{1,2, \ldots, r\}$ with transition matrix $\mathrm{P}=p_{i j}, i$ and $j \in\{1,2$, $\ldots, r\}$, where $p_{i j}=\operatorname{Prob}\left(s_{t+1}=j \mid s_{t}=i\right)$. It is also assumed that $s_{t}$ is periodic and irreducible. Notice that $s_{t}$ may or may not be stationary. If the stationarity assumption is imposed, the above conditions guarantee a unique row-stochastic vector $\pi=\left(\pi_{1}, \pi_{2}, \ldots, \pi_{r}\right)^{\prime}$ such that $\pi \mathrm{P}=\pi$ and $\pi_{i}=\operatorname{Prob}\left(s_{t}=i\right)>$ 0 for all $i \in\{1,2, \ldots, r\}$ and all $t$. Under these assumptions, the model could be referred as a $r$ regime $p$-order Markov-switching autoregressive model (or $\operatorname{MS}(r)$-AR(p) model).

In this paper, it is assumed that both the autoregressive order, $p$, and the regime dimension, $r$, of the $\operatorname{MS}(r)-\operatorname{AR}(p)$ model are unknown, so the interesting issue is to estimate both $p$ and $r$ on the basis of a finite segment $y_{n}=\left(y_{1}, y_{2}, \ldots, y_{T}\right)$ of length $T$ from Equation (1). This paper identifies both $r$ and $p$ by using the following four complexity-penalised likelihood criteria.

$$
\begin{aligned}
& A I C=-2 L+2 k ; \\
& B I C=-2 L+k \log (T) ; \\
& H Q C=-2 L+2 k \log (\log (T)) ; \\
& M S C=-2 L+\sum_{i=1}^{r} \frac{S_{i}\left(S_{i}+\lambda_{i} k\right)}{\delta_{i} S_{i}-\lambda_{i} k-2} ;
\end{aligned}
$$

where $L$ and $T$ are the maximised log likelihood value and the total observations,

$k$ is the number of estimated parameters in the case of AIC, BIC, and HQC; for Markovswitching static models, it is the number of exogenous variables, including an intercept term, $\delta_{i}=\mathrm{E}\left[\pi_{i}^{*} / \hat{\pi}_{i}\right]$ and $\lambda_{i}=\mathrm{E}\left[\left(\pi_{i}^{*} / \hat{\pi}_{i}\right)^{2}\right]$

$\hat{\pi}_{i}$ is the $i^{\text {th }}$ element of the principle eigenvector of $\hat{P} \hat{\pi}=\hat{\pi}$ from the estimation, $\pi_{i}^{*}$ is the $i^{\text {th }}$ element of the principle eigenvector of $\mathrm{P}^{*} \pi^{*}=\pi^{*}$ for the best estimation, and 
$S_{i}$ is the smoother probabilities at regime $i$.

Expectation Maximisation algorithm is used to obtain maximum-likelihood estimates of the model parameters. To implement MSC, we closely follow SNT (2006) to set $\delta_{i}$ and $\lambda_{i}$ to 1 and the total number of regimes (or $r$ ) since they show that the performance of the Monte Carlo simulation with this setting is reasonably satisfactory. Therefore, MSC is calculated as follows:

$$
M S C=-2 L+\sum_{i=1}^{r} \frac{S_{i}\left(S_{i}+r k\right)}{S_{i}-r k-2} .
$$

\section{Simulation and results}

\subsection{Simulation setup}

Here, the simulation settings and selection procedure are described as follows:

(i) Markov-switching autoregressive model: the true model consists of two regimes (or $r=2)$ and one lag with an intercept term in each regime. The true regression coefficients are $v^{\left(s_{t}\right)}=\left(v^{(1)}, v^{(2)}\right)$ and $A^{\left(s_{t}\right)}=\left(A^{(1)}, A^{(2)}\right)$, where $v^{\left(s_{t}\right)}=(0,1)$ and $A^{\left(s_{t}\right)}=(0.3,0.9)$. The $r$-regime variable, $s_{t}$, is a Markov chain with transition probabilities $p_{11}=0.6$ and $p_{22}=0.4$ and the initial probabilities are set to 0.4 and 0.6 . The total number of observations, $T$, is initially set to 200 and $e_{t} \sim \mathrm{N}(0,1)$ and $\sigma^{\left(s_{t}\right)}=\left(\sigma^{(1)}, \sigma^{(2)}\right)=(0.5,0.5)$.

(ii) Markov-switching autoregressive model with small/large coefficient: this paper considers variation from the setting in (i). First, this paper changes the autoregressive coefficient for both regimes to the same value: $v^{\left(s_{t}\right)}=(0,1)$ and $A^{\left(s_{t}\right)}=(0.3,0.3)$. Second, setting the intercept coefficient for both regimes to the same value: $v^{\left(s_{t}\right)}=(0,0)$ and $A^{\left(s_{t}\right)}=(0.3,0.9)$.

(iii) Markov-switching autoregressive model with high/low transition probability: this paper also considers variations from the setting (i) and (ii) by changing the transition probability $p_{11}$ from 0.6 to 0.9 and $p_{22}$ from 0.4 to 0.1 and the initial probabilities from $(0.4,0.6)$ to $(0.5,0.5)$. To 
examine the impact of persistence in $\left\{s_{t}\right\}$, the transition probabilities $p_{11}$ and $p_{22}$ are also set to 0.9 so that their sum is greater than one. ${ }^{3}$

(iv) Markov-switching autoregressive model with small/large sample and high/low noise: the following variations from the setting in (i), (ii), (iii), and (iv) are considered. First, to examine the impact of sample size on performance, this paper conducts the above simulations using $T=$ 100,400 , and 500, respectively. Second, $\sigma^{\left(s_{t}\right)}$ will be set to $(1.0,1.0)$ and $(0.5,1.0)$ for all $T$ to understand the effect of a change in noise level.

(v) Markov-switching autoregressive model with regime-switch in noise level: setting (i) only allows for regime switch in either intercept term or regression coefficient. To consider the effect of switch in noise level, we set $\sigma^{\left(s_{t}\right)}$ to 0.5 if $s_{t}=$ regime 1 and 1 if $s_{t}=$ regime 2 for all $T$.

(vi) Markov-switching static model: the paper also uses the same setting from the autoregressive model in (i) through (v) to examine the performance of the four information criteria applied to Equation (1) where $l$ lagged $y_{t}$ variables are replaced by the same number of exogenous variables, $x_{t}$. These variables are independent and identically distributed random variables with zero mean and unit variance.

The simulations proceed by first generating an artificial time series $y_{t}$ (and exogenous variables, $x_{t}$, in the case of static model) of length $500+T$ according to the setting (i) and (v) and setting initial values to zero. The first 500 pseudo-data points then are discarded in order to eliminate start-up effects, while the remaining $T$ points are used to determine both $r$ and $p$ by minimising the AIC, BIC, HQC, and MSC over $r$ regimes and $p$ lags $(r=1,2,3 ; p=1,2,3)$. Since computations are very intensive, 1000 Monte Carlo replications are carried out for each setting to assess how often the information criteria select the true model.

\footnotetext{
${ }^{3}$ We would like to thank an anonymous referee for suggesting this persistence scenario for us to examine.
} 


\subsection{Simulation results}

\subsubsection{Static Models Results}

Tables 1 to 3 report the frequency of correct state and variable selection for Markov-switching static model with one exogenous variable for different sample size and noise level. Common to these three tables are the assumptions that the number of regimes is two and that initial and transition probabilities are kept constant at $(0.4,0.6)$ and $(0.6,0.4)$, respectively. Notice that Table 1 allows for change in regression coefficient induced by regime change only. In particular, if $s_{t}=$ regime 1 , then the regression coefficient is 0.3 ; if $s_{t}=$ regime 2 , then it is 0.9 . Table 2 allows for change in intercept term the value of which can be either 0 or 1 depending on whether the regime variable is in state 1 or state 2 . Table 3 considers both cases together.

Two main observations can be made before we get into the details of each of these tables. First, BIC consistently outperforms other information criteria regardless of sample size and noise level. The performance of MSC is generally comparable to that of HQC, while AIC seems to be the inferior one. Second, consistent with SNT (2006)'s observation, the frequency of correct states and variables identification for MSC is always higher than that for AIC and the latter has a tendency to retain too many states and variables.

Given that only change in regression coefficient is allowed, Table 1 suggests that BIC is the best and that AIC is always the worst. In a setting where the sample size is 200 with low noise level, for example, the frequency of incorrectly identifying the true model of BIC is 59 (out of 1000) while the relevant frequencies of AIC, HQC, and MSC are 274, 113, and 85, respectively. In addition, BIC has the lowest frequency of identifying the wrong number of variables. An increase in sample size generally leads to better performance. For example, with low noise level and increase in sample size from 100 to 500, the frequency of correct states and variables selection for BIC goes up from 920 to 988, while it also increases from 700 to 805 (AIC), 860 to 945 (HQC), and 893 to 955 
Table 3, where the true model allows for regime change in both intercept term and regression coefficient, basically reinforces observations from Tables 1 and 2. Compared to Table 1, however, Table 3 shows that the performance of all the information criteria is generally poorer. In the case of 400 observations with low noise level, for instance, the frequencies of correct states and variables selection for BIC, AIC, HQC, and MSC are 852, 722, 766, and 799 respectively in Table 3. These numbers are much lower than that in Table 1 because the corresponding numbers are 976, 759, 916, and 946, respectively. Despite this, BIC still stands out from other information criteria with AIC being the worst one.

Table 4 differs from Table 1 in that the transition probabilities change from $(0.6,0.4)$ to $(0.9,0.1)$. This change seems to make the results noisier but it does not have any significant impacts on the main conclusions. Table 5 shows that the change in initial probabilities from $(0.4,0.6)$ to $(0.5,0.5)$ generally leads to a lower performance as well. This paper also considers the case where the sum of diagonal probabilities of transition matrix is greater than one $\left(p_{11}+p_{22}>1\right)$, allowing for persistence in $\left\{s_{t}\right\}$. In this case, the probabilities of regime 1 and regime 2 (or $p_{11}$ and $p_{22}$ ) are set to 
0.9. This change generally lowers the frequency of the true model identification, as reported in Table 6. However, it does not alter the main conclusions.

\title{
3.2.2 Autoregressive models results
}

For Tables 7 to 12 , the data generating process is a two-regime Markov-switching autoregressive model of order one for different sample size, regression coefficient, and noise level. A set of assumptions similar to that of static model is also employed. In particular, Table 7 shows the benchmark case where the initial state probability of state 1 and state 2 are set to 0.4 and 0.6 respectively and the transition probability of moving from state 1 (2) to state 2 (1) is set to $0.4(0.6)$. Notice that Table 7 allows for change in regression coefficient only. The case allowing for change in intercept term is presented in Table 8. Table 9 allows for both intercept term and regression coefficient to be regime-specific. Table 10 considers the case where there is a change in transition probabilities from $(0.6,0.4)$ to $(0.9,0.1)$ while Table 11 deals with a change in the initial probabilities. Table 12 shows the results for the case where $\left\{s_{t}\right\}$ is allowed to be persistent.

\begin{abstract}
Allowing for change in regression coefficient only, Table 7 shows that BIC is the best among the four information criteria. For example, if the sample size is 100 and the noise level is low, the number of times that BIC correctly identifies the true model is 852 (out of 1000) while the relevant frequencies of AIC, HQC, and MSC are 696, 733, and 772, respectively. When the noise level increases, the performance becomes worse; however, this effect is not significant. BIC is still the best choice while MSC is as good as HQC. AIC comes last because it is too generous in retaining many regimes and variables. In addition, an increase in sample size does help improve the performance. For instance, the frequency of correct model identification for BIC, AIC, HQC, and MSC increases from 844, 600, 694, and 644 to 948, 706, 859, and 907 respectively when the sample size increases from 100 to 500 and the noise level is high.
\end{abstract}


Comparison between Tables 1 and 7 reveals that MSC is more suitable for static model than for autoregressive model because the frequency of correctly identifying the true model is generally higher in static model. Consistent with SNT (2006)'s claim that MSC can also be used in autoregressive model, MSC still outperforms AIC and HQC.

Table 7 shows that the performance is always better than that in Table 8 when allowing for regimechange in variance, despite that its overall results are broadly similar to that of Table 8 . With 500 observations and switch in noise level, for instance, the frequency of correctly selecting the true model for BIC, AIC, HQC, and MSC decreases from 986, 784, 921, and 945 as in Table 7 to 964 , 750, 865, and 901 as in Table 8, respectively. Compared to Table 7, Table 9 shows that the performance of all the information criteria becomes slightly worse when both intercept term and regression coefficient are allowed to be regime switching. All of these tables clearly indicate that as far as performance is concerned, BIC always comes first, closely followed by MSC and HQC, and then AIC.

Change in transition probabilities from $(0.6,0.4)$ to $(0.9,0.1)$, as shown in Table 10 , generally leads to a slightly improved performance. The comparison between Tables 7 and 11 reveals that change in the initial probabilities from $(0.4,0.6)$ to $(0.1,0.9)$ leads to a marginally deteriorated performance but it does not change main conclusions. In addition, persistence in $\left\{s_{t}\right\}$ generally lowers the frequency of selecting the true model as depicted in Table 12. However, the main conclusions are still the same.

\section{Conclusions and practical recommendation}

The simulations have shown that in the context of jointly determination of number of states and number of variables in Markov-switching models BIC has better performance over MSC, HQC, and 


\begin{abstract}
AIC. The performance of MSC is comparable to that of HQC while AIC is always inferior. We therefore recommend that BIC should be used in practical applications.
\end{abstract}

\title{
References
}

Hamilton, J. D. (1989). A new approach to the economic analysis of nonstationary time series and the business cycle. Econometrica 57(2): 357-384.

Psaradakis, Z., Spagnolo, N. (2006). Joint determination of the state dimension and autoregressive order for models with Markov regime switching. Journal of Time Series Analysis 27(5): 753-766.

Smith, A., Naik P. A., Tsai, C. (2006). Markov-switching model selection using Kullback-Leibler divergence. Journal of Econometrics 134(2): 553-577.

Timmermann, A. (2000). Moments of Markov switching models. Journal of Econometrics 96(1): 75-111. 
1

4

5

6

Table 1: Frequency of selection of a MS(2) static model - Change in regression coefficient The data generating process is the MS static model with two regimes and one exogenous variable shown as follows:

$$
y_{t}=v^{\left(s_{t}\right)}+A^{\left(s_{t}\right)} x_{t}+\sigma^{\left(s_{t}\right)} e_{t} \text {. }
$$

The initial probabilities are set to 0.4 and 0.6 with the transition probabilities as $p_{11}=0.6 ; p_{22}=0.4$. The true regression coefficients are $v^{\left(s_{t}\right)}=\left(v^{(1)}, v^{(2)}\right)$ and $A^{\left(s_{t}\right)}=\left(A^{(1)}, A^{(2)}\right)$, where $v^{\left(s_{t}\right)}=(0,0)$ and $A^{\left(s_{t}\right)}=(0.3,0.9)$. Notice that the total replication is 1000 .

The first column shows the possible values that $\sigma^{\left(s_{t}\right)}$ can take. Notice that in the regime-specific case, $\sigma^{\left(s_{t}\right)}$ is set to 0.5 if $s_{t}=$ regime 1 and 1 if $s_{t}=$ regime 2. The second column shows the relevant information criterion being considered, while the third column indicates the number of regimes imposed on estimation. With sample size of 100, the fourth column depicts the frequency of selecting the correct number of variable (in this case, 1 variable) while the fifth column indicates the frequency of selecting the incorrect number of variables (in this case, 2 variables). Other columns show similar frequencies for different sample sizes.

\begin{tabular}{|c|c|c|c|c|c|c|c|c|c|c|}
\hline \multirow{2}{*}{ Sigma } & \multirow{2}{*}{$\begin{array}{c}\text { Information } \\
\text { criteria }\end{array}$} & \multirow{2}{*}{$\begin{array}{l}\text { No. of } \\
\text { regimes } \\
\text { imposed }\end{array}$} & \multicolumn{2}{|c|}{100 observations } & \multicolumn{2}{|c|}{200 observations } & \multicolumn{2}{|c|}{400 observations } & \multicolumn{2}{|c|}{500 observations } \\
\hline & & & 1 variable & 2 variables & 1 variable & 2 variables & 1 variable & 2 variables & 1 variable & 2 variables \\
\hline \multirow[t]{12}{*}{0.5} & \multirow[t]{3}{*}{ AIC } & 1 & 1 & 11 & 1 & 5 & 3 & 28 & 0 & 12 \\
\hline & & 2 & 700 & 247 & 726 & 210 & 759 & 88 & 805 & 107 \\
\hline & & 3 & 24 & 17 & 5 & 53 & 41 & 81 & 60 & 16 \\
\hline & \multirow[t]{3}{*}{$\mathrm{BIC}$} & 1 & 4 & 1 & 6 & 1 & 3 & 1 & 1 & 1 \\
\hline & & 2 & 920 & 75 & 941 & 52 & 976 & 20 & 988 & 10 \\
\hline & & 3 & 0 & 0 & 0 & 0 & 0 & 0 & 0 & 0 \\
\hline & \multirow[t]{3}{*}{$\overline{\mathrm{HQC}}$} & 1 & 5 & 1 & 1 & 0 & 1 & 1 & 1 & 0 \\
\hline & & 2 & 860 & 133 & 887 & 109 & 916 & 75 & 945 & 48 \\
\hline & & 3 & 0 & 1 & 0 & 3 & 5 & 2 & 5 & 1 \\
\hline & \multirow[t]{3}{*}{ MSC } & 1 & 1 & 11 & 2 & 19 & 1 & 0 & 1 & 0 \\
\hline & & 2 & 893 & 32 & 915 & 63 & 946 & 44 & 955 & 41 \\
\hline & & 3 & 23 & 40 & 0 & 1 & 8 & 1 & 3 & 0 \\
\hline \multirow[t]{12}{*}{1.0} & \multirow[t]{3}{*}{ AIC } & 1 & 0 & 10 & 2 & 15 & 2 & 18 & 3 & 15 \\
\hline & & 2 & 697 & 258 & 710 & 250 & 753 & 199 & 801 & 81 \\
\hline & & 3 & 10 & 25 & 0 & 23 & 2 & 26 & 100 & 0 \\
\hline & \multirow[t]{3}{*}{ BIC } & 1 & 4 & 4 & 1 & 1 & 1 & 1 & 1 & 1 \\
\hline & & 2 & 911 & 81 & 934 & 64 & 967 & 31 & 984 & 11 \\
\hline & & 3 & 0 & 0 & 0 & 0 & 0 & 0 & 3 & 0 \\
\hline & \multirow[t]{3}{*}{$\mathrm{HQC}$} & 1 & 1 & 23 & 1 & 24 & 1 & 13 & 2 & 17 \\
\hline & & 2 & 814 & 152 & 870 & 100 & 880 & 106 & 890 & 88 \\
\hline & & 3 & 10 & 0 & 0 & 5 & 0 & 0 & 3 & 0 \\
\hline & \multirow[t]{3}{*}{ MSC } & 1 & 7 & 1 & 1 & 4 & 1 & 0 & 1 & 0 \\
\hline & & 2 & 883 & 57 & 904 & 75 & 928 & 70 & 938 & 1 \\
\hline & & 3 & 15 & 37 & 1 & 15 & 0 & 1 & 60 & 0 \\
\hline \multirow{12}{*}{$\begin{array}{l}\text { Regime- } \\
\text { specific }\end{array}$} & \multirow[t]{3}{*}{$\mathrm{AIC}$} & 1 & 1 & 10 & 2 & 18 & 1 & 3 & 1 & 5 \\
\hline & & 2 & 652 & 290 & 671 & 226 & 680 & 242 & 753 & 190 \\
\hline & & 3 & 0 & 47 & 3 & 80 & 8 & 66 & 3 & 48 \\
\hline & \multirow[t]{3}{*}{$\mathrm{BIC}$} & 1 & 4 & 1 & 2 & 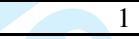 & 4 & 1 & 1 & 1 \\
\hline & & 2 & 884 & 108 & 937 & 60 & 953 & 42 & 962 & 36 \\
\hline & & 3 & 0 & 3 & 0 & 0 & 0 & 0 & 0 & 0 \\
\hline & \multirow[t]{3}{*}{ HQC } & 1 & 1 & 25 & 1 & 1 & 1 & 0 & 2 & 0 \\
\hline & & 2 & 802 & 160 & 860 & 124 & 865 & 123 & 890 & 103 \\
\hline & & 3 & 0 & 12 & 2 & 12 & 1 & 10 & 1 & 4 \\
\hline & \multirow[t]{3}{*}{ MSC } & 1 & 5 & 1 & 2 & 1 & 1 & 2 & 1 & 0 \\
\hline & & 2 & 856 & 59 & 885 & 67 & 924 & 65 & 927 & 68 \\
\hline & & 3 & 2 & 77 & 4 & 41 & 2 & 6 & 1 & 3 \\
\hline
\end{tabular}


Table 2: Frequency of selection of a MS(2) static model - Change in intercept term

The true data generating process is the MS static model with two regimes and one exogenous variable, as follows:

$$
y_{t}=v^{\left(s_{t}\right)}+A^{\left(s_{t}\right)} x_{t}+\sigma^{\left(s_{t}\right)} e_{t} .
$$

The initial probabilities are set to 0.4 and 0.6 with the transition probabilities as $p_{11}=0.6 ; p_{22}=0.4$. The true regression coefficient coefficients are $v^{\left(s_{t}\right)}=\left(v^{(1)}, v^{(2)}\right)$ and $A^{\left(s_{t}\right)}=\left(A^{(1)}, A^{(2)}\right)$, where $v^{\left(s_{t}\right)}=(0,1)$ and $A^{\left(s_{t}\right)}=(0.3,0.3)$. Notice that the total replication is 1000.

The first column shows the possible values that $\sigma^{\left(s_{t}\right)}$ can take. Notice that in the regime-specific case, $\sigma^{\left(s_{t}\right)}$ is set to 0.5 if $s_{t}=$ regime 1 and 1 if $s_{t}=$ regime 2. The second column shows the relevant information criterion being considered, while the third column indicates the number of regimes imposed on estimation. With sample size of 100, the fourth column depicts the frequency of selecting the correct number of variable (in this case, 1 variable) while the fifth column indicates the frequency of selecting the incorrect number of variables (in this case, 2 variables). Other columns show similar frequencies for different sample sizes.

\begin{tabular}{|c|c|c|c|c|c|c|c|c|c|c|}
\hline \multirow{2}{*}{ Sigma } & \multirow{2}{*}{$\begin{array}{c}\text { Information } \\
\text { criteria }\end{array}$} & \multirow{2}{*}{$\begin{array}{l}\text { No. of } \\
\text { regimes } \\
\text { imposed }\end{array}$} & \multicolumn{2}{|c|}{100 observations } & \multicolumn{2}{|c|}{200 observations } & \multicolumn{2}{|c|}{400 observations } & \multicolumn{2}{|c|}{500 observations } \\
\hline & & & 1 variable & 2 variables & 1 variable & 2 variables & 1 variable & 2 variables & 1 variable & 2 variables \\
\hline \multirow[t]{12}{*}{0.5} & AIC & 1 & 0 & 41 & 1 & 31 & 1 & 17 & 1 & 7 \\
\hline & & 2 & 714 & 162 & 790 & 26 & 822 & 40 & 840 & 72 \\
\hline & & 3 & 73 & 10 & 152 & 0 & 40 & 80 & 54 & 26 \\
\hline & $\mathrm{BIC}$ & 1 & 1 & 0 & 1 & 0 & 1 & 0 & 1 & 0 \\
\hline & & 2 & 930 & 61 & 954 & 42 & 980 & 18 & 990 & 9 \\
\hline & & 3 & 7 & 1 & 3 & 0 & 1 & 0 & 0 & 0 \\
\hline & HQC & 1 & 1 & 3 & 1 & 9 & 1 & 5 & 1 & 7 \\
\hline & & 2 & 820 & 133 & 840 & 109 & 870 & 55 & 890 & 60 \\
\hline & & 3 & 41 & 2 & 41 & 0 & 60 & 9 & 30 & 12 \\
\hline & MSC & 1 & 6 & 5 & 1 & 0 & 1 & 0 & 1 & 0 \\
\hline & & 2 & 915 & 32 & 934 & 15 & 950 & 9 & 978 & 0 \\
\hline & & 3 & 34 & 8 & 49 & 1 & 39 & 1 & 21 & 0 \\
\hline \multirow[t]{12}{*}{1.0} & AIC & 1 & 2 & 20 & 0 & 15 & 0 & 2 & 0 & 6 \\
\hline & & 2 & 701 & 215 & 714 & 148 & 734 & 130 & 787 & 141 \\
\hline & & 3 & 56 & 6 & 80 & 43 & 79 & 55 & 32 & 34 \\
\hline & BIC & 1 & 0 & 0 & 0 & 0 & 1 & 0 & 0 & 0 \\
\hline & & 2 & 900 & 100 & 959 & 41 & 977 & 20 & 984 & 14 \\
\hline & & 3 & 0 & 0 & 0 & 0 & 2 & 0 & 2 & 0 \\
\hline & HQC & 1 & 4 & 5 & 1 & 8 & 0 & 7 & 2 & 3 \\
\hline & & 2 & 830 & 153 & 850 & 132 & 890 & 57 & 912 & 66 \\
\hline & & 3 & 8 & 0 & 7 & 2 & 40 & 6 & 16 & 1 \\
\hline & MSC & 1 & 1 & 5 & 1 & 1 & 0 & 0 & 0 & 0 \\
\hline & & 2 & 880 & 24 & 900 & 83 & 911 & 41 & 917 & 46 \\
\hline & & 3 & 69 & 21 & 14 & 1 & 47 & 1 & 36 & 1 \\
\hline \multirow{12}{*}{$\begin{array}{l}\text { Regime- } \\
\text { specific }\end{array}$} & AIC & 1 & 0 & 34 & 11 & 18 & 8 & 11 & 0 & 6 \\
\hline & & 2 & 701 & 104 & 713 & 142 & 730 & 102 & 790 & 119 \\
\hline & & 3 & 157 & 4 & 56 & 60 & 53 & 96 & 26 & 59 \\
\hline & BIC & 1 & 2 & 0 & 0 & 0 & 1 & 0 & 2 & 0 \\
\hline & & 2 & 902 & 32 & 918 & 30 & 950 & 19 & 968 & 20 \\
\hline & & 3 & 64 & 0 & 52 & 0 & 30 & 0 & 9 & 1 \\
\hline & HQC & 1 & 10 & 4 & 8 & 7 & 4 & 6 & 0 & 11 \\
\hline & & 2 & 800 & 85 & 840 & 85 & 856 & 83 & 865 & 42 \\
\hline & & 3 & 100 & 1 & 50 & 10 & 45 & 6 & 66 & 16 \\
\hline & MSC & 1 & 3 & 2 & 1 & 6 & 0 & 1 & 0 & 0 \\
\hline & & 2 & 832 & 45 & 854 & 70 & 890 & 32 & 908 & 28 \\
\hline & & 3 & 89 & 29 & 37 & 32 & 75 & 2 & 59 & 5 \\
\hline
\end{tabular}


1

4

5

6

7

8

9

10

11

12

13

14

15

16

17

18

19

20

21

22

23

24

25

26

27

28

29

30

31

32

33

34

35

36

Table 3: Frequency of selection of a MS(2) static model - Changes in intercept term and regression coefficient The true data generating process is the MS static model with two regimes and one exogenous variable, as follows:

$$
y_{t}=v^{\left(s_{t}\right)}+A^{\left(s_{t}\right)} x_{t}+\sigma^{\left(s_{t}\right)} e_{t} \text {. }
$$

The initial probabilities are set to 0.4 and 0.6 with the transition probabilities as $p_{11}=0.6 ; p_{22}=0.4$. The true regression coefficients are $v^{\left(s_{t}\right)}=\left(v^{(1)}, v^{(2)}\right)$ and $A^{\left(s_{t}\right)}=\left(A^{(1)}, A^{(2)}\right)$, where $v^{\left(s_{t}\right)}=(0,1)$ and $A^{\left(s_{t}\right)}=(0.3,0.9)$. Notice that the total replication is 1000 .

The first column shows the possible values that $\sigma^{\left(s_{t}\right)}$ can take. Notice that in the regime-specific case, $\sigma^{\left(s_{t}\right)}$ is set to 0.5 if $s_{t}=$ regime 1 and 1 if $s_{t}=$ regime 2. The second column shows the relevant information criterion being considered, while the third column indicates the number of regimes imposed on estimation. With sample size of 100, the fourth column depicts the frequency of selecting the correct number of variable (in this case, 1 variable) while the fifth column indicates the frequency of selecting the incorrect number of variables (in this case, 2 variables). Other columns show similar frequencies for different sample sizes.

\begin{tabular}{|c|c|c|c|c|c|c|c|c|c|c|}
\hline \multirow{2}{*}{ Sigma } & \multirow{2}{*}{$\begin{array}{c}\text { Information } \\
\text { criteria }\end{array}$} & \multirow{2}{*}{$\begin{array}{c}\text { No. of } \\
\text { regimes } \\
\text { imposed }\end{array}$} & \multicolumn{2}{|c|}{100 observations } & \multicolumn{2}{|c|}{200 observations } & \multicolumn{2}{|c|}{400 observations } & \multicolumn{2}{|c|}{500 observations } \\
\hline & & & 1 variable & 2 variables & 1 variable & 2 variables & 1 variable & 2 variables & 1 variable & 2 variables \\
\hline \multirow[t]{12}{*}{0.5} & \multirow[t]{3}{*}{$\mathrm{AIC}$} & 1 & 3 & 24 & 5 & 20 & 0 & 7 & 2 & 3 \\
\hline & & 2 & 601 & 226 & 660 & 264 & 722 & 205 & 792 & 181 \\
\hline & & 3 & 136 & 10 & 10 & 41 & 49 & 17 & 11 & 11 \\
\hline & \multirow[t]{3}{*}{$\mathrm{BIC}$} & 1 & 6 & 4 & 5 & 2 & 0 & 0 & 1 & 0 \\
\hline & & 2 & 752 & 236 & 785 & 208 & 852 & 134 & 916 & 69 \\
\hline & & 3 & 2 & 0 & 0 & 0 & 14 & 0 & 13 & 1 \\
\hline & \multirow[t]{3}{*}{ HQC } & 1 & 0 & 3 & 0 & 7 & 0 & 3 & 1 & 1 \\
\hline & & 2 & 665 & 301 & 733 & 241 & 766 & 123 & 805 & 82 \\
\hline & & 3 & 28 & 3 & 8 & 11 & 85 & 23 & 65 & 46 \\
\hline & \multirow[t]{3}{*}{ MSC } & 1 & 6 & 6 & 2 & 1 & 0 & 0 & 0 & 1 \\
\hline & & 2 & 745 & 130 & 755 & 215 & 799 & 111 & 838 & 100 \\
\hline & & 3 & 83 & 30 & 12 & 15 & 87 & 3 & 60 & 1 \\
\hline \multirow[t]{12}{*}{1.0} & \multirow[t]{3}{*}{ AIC } & 1 & 0 & 15 & 3 & 15 & 0 & 5 & 4 & 16 \\
\hline & & 2 & 519 & 253 & 570 & 242 & 650 & 147 & 792 & 114 \\
\hline & & 3 & 180 & 33 & 150 & 20 & 108 & 90 & 24 & 50 \\
\hline & \multirow[t]{3}{*}{ BIC } & 1 & 6 & 3 & 1 & 0 & 3 & 1 & 9 & 1 \\
\hline & & 2 & 667 & 320 & 711 & 287 & 834 & 160 & 906 & 81 \\
\hline & & 3 & 3 & 1 & 1 & 0 & 1 & 1 & 2 & 1 \\
\hline & \multirow[t]{3}{*}{ HQC } & 1 & 9 & 8 & 1 & 21 & 4 & 0 & 0 & 0 \\
\hline & & 2 & 630 & 302 & 656 & 202 & 770 & 181 & 820 & 132 \\
\hline & & 3 & 37 & 14 & 78 & 42 & 17 & 28 & 39 & 9 \\
\hline & \multirow[t]{3}{*}{ MSC } & 1 & 2 & 7 & 3 & 1 & 0 & 0 & 0 & 0 \\
\hline & & 2 & 631 & 294 & 640 & 260 & 707 & 175 & 801 & 17 \\
\hline & & 3 & 11 & 55 & 46 & 50 & 104 & 14 & 181 & 1 \\
\hline \multirow{12}{*}{$\begin{array}{l}\text { Regime- } \\
\text { specific }\end{array}$} & \multirow[t]{3}{*}{ AIC } & 1 & 11 & 29 & 0 & 37 & 6 & 10 & 0 & 4 \\
\hline & & 2 & 558 & 310 & 629 & 236 & 705 & 159 & 754 & 130 \\
\hline & & 3 & 64 & 28 & 96 & 2 & 28 & 92 & 38 & 74 \\
\hline & \multirow[t]{3}{*}{ BIC } & 1 & 8 & 1 & 6 & 4 & 2 & 0 & 1 & 0 \\
\hline & & 2 & 772 & 216 & 838 & 151 & 887 & 110 & 989 & 7 \\
\hline & & 3 & 3 & 0 & 1 & 0 & 1 & 0 & 3 & 0 \\
\hline & \multirow[t]{3}{*}{ HQC } & 1 & 7 & 4 & 0 & 1 & 1 & 2 & 0 & 3 \\
\hline & & 2 & 633 & 290 & 722 & 136 & 800 & 171 & 809 & 152 \\
\hline & & 3 & 62 & 4 & 125 & 16 & 17 & 9 & 32 & 4 \\
\hline & \multirow[t]{3}{*}{ MSC } & 1 & 5 & 5 & 2 & 7 & 0 & 0 & 0 & 0 \\
\hline & & 2 & 687 & 170 & 771 & 165 & 800 & 157 & 803 & 128 \\
\hline & & 3 & 73 & 60 & 21 & 34 & 42 & 1 & 69 & 0 \\
\hline
\end{tabular}


Table 4: Frequency of selection of a MS(2) static model - Change in transition probabilities

The true data generating process is the MS static model with two regimes and one exogenous variable, as follows:

$$
y_{t}=v^{\left(s_{t}\right)}+A^{\left(s_{t}\right)} x_{t}+\sigma^{\left(s_{t}\right)} e_{t} \text {. }
$$

The initial probabilities are set to 0.4 and 0.6 with the transition probabilities as $p_{11}=0.9 ; p_{22}=0.1$. The true regression coefficients are $v^{\left(s_{t}\right)}=\left(v^{(1)}, v^{(2)}\right)$ and $A^{\left(s_{t}\right)}=\left(A^{(1)}, A^{(2)}\right)$, where $v^{\left(s_{t}\right)}=(0,0)$ and $A^{\left(s_{t}\right)}=(0.3,0.9)$. Notice that the total replication is 1000

The first column shows the possible values that $\sigma^{\left(s_{t}\right)}$ can take. Notice that in the regime-specific case, $\sigma^{\left(s_{t}\right)}$ is set to 0.5 if $s_{t}=$ regime 1 and 1 if $s_{t}=$ regime 2. The second column shows the relevant information criterion being considered, while the third column indicates the number of regimes imposed on estimation. With sample size of 100, the fourth column depicts the frequency of selecting the correct number of variable (in this case, 1 variable) while the fifth column indicates the frequency of selecting the incorrect number of variables (in this case, 2 variables). Other columns show similar frequencies for different sample sizes.

\begin{tabular}{|c|c|c|c|c|c|c|c|c|c|c|}
\hline \multirow{2}{*}{ Sigma } & \multirow{2}{*}{$\begin{array}{c}\text { Information } \\
\text { criteria }\end{array}$} & \multirow{2}{*}{$\begin{array}{l}\text { No. of } \\
\text { regimes } \\
\text { imposed }\end{array}$} & \multicolumn{2}{|c|}{100 observations } & \multicolumn{2}{|c|}{200 observations } & \multicolumn{2}{|c|}{400 observations } & \multicolumn{2}{|c|}{500 observations } \\
\hline & & & 1 variable & 2 variables & 1 variable & 2 variables & 1 variable & 2 variables & 1 variable & 2 variables \\
\hline \multirow[t]{12}{*}{0.5} & \multirow[t]{3}{*}{ AIC } & 1 & 3 & 6 & 0 & 13 & 5 & 5 & 0 & 5 \\
\hline & & 2 & 711 & 250 & 764 & 151 & 792 & 178 & 807 & 154 \\
\hline & & 3 & 0 & 30 & 22 & 50 & 1 & 19 & 0 & 34 \\
\hline & \multirow[t]{3}{*}{$\mathrm{BIC}$} & 1 & 5 & 2 & 1 & 0 & 0 & 0 & 0 & $\overline{0}$ \\
\hline & & 2 & 842 & 151 & 870 & 129 & 979 & 21 & 988 & 12 \\
\hline & & 3 & 0 & 0 & 0 & 0 & 0 & 0 & 0 & 0 \\
\hline & \multirow[t]{3}{*}{$\overline{\mathrm{HQC}}$} & 1 & 1 & 5 & 4 & 4 & 4 & 3 & 0 & 0 \\
\hline & & 2 & 740 & 250 & 802 & 174 & 815 & 173 & 842 & 154 \\
\hline & & 3 & 0 & 4 & 5 & 11 & 5 & 0 & 0 & 4 \\
\hline & \multirow[t]{3}{*}{ MSC } & 1 & 2 & 9 & 2 & 5 & 0 & 1 & 0 & 0 \\
\hline & & 2 & 829 & 120 & 840 & 92 & 947 & 48 & 977 & 22 \\
\hline & & 3 & 10 & 30 & 29 & 32 & 0 & 4 & 0 & 1 \\
\hline \multirow[t]{12}{*}{1.0} & \multirow[t]{3}{*}{ AIC } & 1 & 3 & 4 & 5 & 7 & 0 & 4 & 0 & 9 \\
\hline & & 2 & 690 & 281 & 750 & 228 & 815 & 176 & 841 & 140 \\
\hline & & 3 & 0 & 22 & 0 & 10 & 0 & 5 & 0 & 10 \\
\hline & \multirow[t]{3}{*}{$\mathrm{BIC}$} & 1 & 4 & 5 & 7 & 3 & 6 & 4 & 0 & 0 \\
\hline & & 2 & 826 & 165 & 856 & 134 & 870 & 120 & 885 & 115 \\
\hline & & 3 & 0 & 0 & 0 & 0 & 0 & 0 & 0 & 0 \\
\hline & \multirow[t]{3}{*}{$\overline{\mathrm{HQC}}$} & 1 & 4 & 2 & 3 & 4 & 3 & 6 & 0 & 0 \\
\hline & & 2 & 730 & 264 & 791 & 201 & 830 & 161 & 844 & 156 \\
\hline & & 3 & 0 & 0 & 0 & 1 & 0 & 0 & 0 & 0 \\
\hline & \multirow[t]{3}{*}{ MSC } & 1 & 6 & 2 & 5 & 5 & 6 & 4 & 0 & 0 \\
\hline & & 2 & 799 & 138 & 836 & 147 & 850 & 139 & 859 & 141 \\
\hline & & 3 & 12 & 43 & 0 & 7 & 0 & 1 & 0 & 0 \\
\hline \multirow{12}{*}{$\begin{array}{l}\text { Regime- } \\
\text { specific }\end{array}$} & \multirow[t]{3}{*}{ AIC } & 1 & 2 & 4 & 3 & 6 & 3 & 6 & 0 & 8 \\
\hline & & 2 & 682 & 291 & 747 & 200 & 761 & 135 & 842 & 70 \\
\hline & & 3 & 12 & 9 & 2 & 42 & 29 & 66 & 10 & 70 \\
\hline & \multirow[t]{3}{*}{ BIC } & 1 & 1 & 3 & 2 & 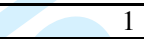 & 1 & 0 & 0 & 0 \\
\hline & & 2 & 856 & 135 & 943 & 54 & 950 & 42 & 974 & 26 \\
\hline & & 3 & 1 & 4 & 0 & 0 & 5 & 2 & 0 & 0 \\
\hline & \multirow[t]{3}{*}{$\overline{\mathrm{HQC}}$} & 1 & 8 & 1 & 9 & 0 & 2 & 0 & 1 & 0 \\
\hline & & 2 & 790 & 170 & 800 & 190 & 881 & 66 & 907 & 81 \\
\hline & & 3 & 11 & 20 & 0 & 1 & 21 & 30 & 4 & 7 \\
\hline & \multirow[t]{3}{*}{ MSC } & 1 & 2 & 3 & 2 & 1 & 1 & 2 & 0 & $\overline{0}$ \\
\hline & & 2 & 850 & 100 & 907 & 48 & 911 & 56 & 938 & 56 \\
\hline & & 3 & 13 & 32 & 12 & 30 & 14 & 16 & 4 & 2 \\
\hline
\end{tabular}


1

Table 5: Frequency of selection of a MS(2) static model - Change in initial probabilities

The true data generating process is the MS static model with two regimes and one exogenous variable, as follows:

$$
y_{t}=v^{\left(s_{s}\right)}+A^{\left(s_{t}\right)} x_{t}+\sigma^{\left(s_{s}\right)} e_{t} \text {. }
$$

The initial probabilities are set to 0.5 and 0.5 with the transition probabilities as $p_{11}=0.6 ; p_{22}=0.4$. The true regression coefficients are $v^{\left(s_{t}\right)}=\left(v^{(1)}, v^{(2)}\right)$ and $A^{\left(s_{t}\right)}=\left(A^{(1)}, A^{(2)}\right)$, where $v^{\left(s_{t}\right)}=(0,0)$ and $A^{\left(s_{t}\right)}=(0.3,0.9)$. Notice that the total replication is 1000

The first column shows the possible values that $\sigma^{\left(s_{t}\right)}$ can take. Notice that in the regime-specific case, $\sigma^{\left(s_{t}\right)}$ is set to 0.5 if $s_{t}=$ regime 1 and 1 if $s_{t}=$ regime 2. The second column shows the relevant information criterion being considered, while the third column indicates the number of regimes imposed on estimation. With sample size of 100, the fourth column depicts the frequency of selecting the correct number of variable (in this case, 1 variable) while the fifth column indicates the frequency of selecting the incorrect number of variables (in this case, 2 variables). Other columns show similar frequencies for different sample sizes.

\begin{tabular}{|c|c|c|c|c|c|c|c|c|c|c|}
\hline \multirow{2}{*}{ Sigma } & \multirow{2}{*}{$\begin{array}{c}\text { Information } \\
\text { criteria }\end{array}$} & \multirow{2}{*}{$\begin{array}{l}\text { No. of } \\
\text { regimes } \\
\text { imposed }\end{array}$} & \multicolumn{2}{|c|}{100 observations } & \multicolumn{2}{|c|}{200 observations } & \multicolumn{2}{|c|}{400 observations } & \multicolumn{2}{|c|}{500 observations } \\
\hline & & & 1 variable & 2 variables & 1 variable & 2 variables & 1 variable & 2 variables & 1 variable & 2 variables \\
\hline \multirow[t]{12}{*}{0.5} & \multirow[t]{3}{*}{$\mathrm{AIC}$} & 1 & 4 & 8 & 5 & 4 & 2 & 4 & 1 & 2 \\
\hline & & 2 & 682 & 217 & 694 & 221 & 737 & 158 & 796 & 158 \\
\hline & & 3 & 25 & 64 & 2 & 74 & 8 & 91 & 2 & 41 \\
\hline & \multirow[t]{3}{*}{$\mathrm{BIC}$} & 1 & 5 & 2 & 2 & 0 & 1 & 0 & 0 & 0 \\
\hline & & 2 & 850 & 143 & 884 & 114 & 917 & 82 & 976 & 24 \\
\hline & & 3 & 0 & 0 & 0 & 0 & 0 & 0 & 0 & 0 \\
\hline & \multirow[t]{3}{*}{ HQC } & 1 & 3 & 0 & 4 & 1 & 2 & 5 & 2 & 0 \\
\hline & & 2 & 750 & 232 & 769 & 213 & 820 & 167 & 921 & 69 \\
\hline & & 3 & 5 & 10 & 0 & 13 & 1 & 5 & 0 & 8 \\
\hline & \multirow[t]{3}{*}{ MSC } & 1 & 6 & 9 & 8 & 2 & 0 & 0 & 0 & 0 \\
\hline & & 2 & 800 & 80 & 854 & 84 & 865 & 134 & 948 & 50 \\
\hline & & 3 & 25 & 80 & 2 & 50 & 1 & 0 & 0 & 2 \\
\hline \multirow[t]{12}{*}{1.0} & \multirow[t]{3}{*}{ AIC } & 1 & 2 & 34 & 4 & 37 & 0 & 7 & 0 & 8 \\
\hline & & 2 & 633 & 280 & 655 & 261 & 719 & 237 & 773 & 205 \\
\hline & & 3 & 3 & 48 & 21 & 22 & 11 & 26 & 0 & 14 \\
\hline & \multirow[t]{3}{*}{$\mathrm{BIC}$} & 1 & 3 & 0 & 2 & 1 & 2 & 0 & 0 & 0 \\
\hline & & 2 & 826 & 170 & 854 & 143 & 866 & 132 & 969 & 31 \\
\hline & & 3 & 0 & 1 & 0 & 0 & 0 & 0 & 0 & 0 \\
\hline & \multirow[t]{3}{*}{ HQC } & 1 & 5 & 1 & 2 & 8 & 1 & 7 & 1 & 1 \\
\hline & & 2 & 733 & 252 & 754 & 232 & 812 & 179 & 892 & 105 \\
\hline & & 3 & 0 & 9 & 0 & 4 & 0 & 1 & 0 & 1 \\
\hline & \multirow[t]{3}{*}{ MSC } & 1 & 1 & 5 & 0 & 9 & 0 & 0 & 0 & 0 \\
\hline & & 2 & 750 & 183 & 800 & 181 & 854 & 145 & 921 & 79 \\
\hline & & 3 & 8 & 53 & 0 & 10 & 0 & 1 & 0 & 0 \\
\hline \multirow{12}{*}{$\begin{array}{l}\text { Regime- } \\
\text { specific }\end{array}$} & \multirow[t]{3}{*}{ AIC } & 1 & 2 & 9 & 3 & 4 & 0 & 7 & 2 & 2 \\
\hline & & 2 & 786 & 150 & 803 & 160 & 817 & 152 & 823 & 110 \\
\hline & & 3 & 1 & 52 & 0 & 30 & 3 & 21 & 2 & 61 \\
\hline & \multirow[t]{3}{*}{ BIC } & 1 & 5 & 4 & 6 & 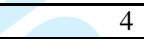 & 3 & 2 & 1 & 0 \\
\hline & & 2 & 913 & 78 & 946 & 43 & 953 & 42 & 960 & 39 \\
\hline & & 3 & 0 & 0 & 0 & 1 & 0 & 0 & 0 & 0 \\
\hline & \multirow[t]{3}{*}{$\overline{\mathrm{HQC}}$} & 1 & 9 & 1 & 4 & 5 & 3 & 1 & 0 & 0 \\
\hline & & 2 & 816 & 168 & 850 & 140 & 871 & 124 & 883 & 108 \\
\hline & & 3 & 0 & 6 & 0 & 1 & 0 & 1 & 1 & 8 \\
\hline & \multirow[t]{3}{*}{ MSC } & 1 & 3 & 7 & 1 & 6 & 0 & 0 & 0 & 0 \\
\hline & & 2 & 832 & 38 & 849 & 130 & 903 & 96 & 911 & 78 \\
\hline & & 3 & 13 & 107 & 1 & 13 & 0 & 1 & 0 & 11 \\
\hline
\end{tabular}


Table 6: Frequency of selection of a MS(2) static model - Persistence in $\left\{s_{t}\right\}$

The true data generating process is the MS static model with two regimes and one exogenous variable, as follows:

$$
y_{t}=v^{\left(s_{t}\right)}+A^{\left(s_{t}\right)} x_{t}+\sigma^{\left(s_{t}\right)} e_{t} .
$$

The initial probabilities are set to 0.4 and 0.6 with the transition probabilities as $p_{11}=0.9 ; p_{22}=0.9$. The true regression coefficients are $v^{\left(s_{t}\right)}=\left(v^{(1)}, v^{(2)}\right)$ and $A^{\left(s_{t}\right)}=\left(A^{(1)}, A^{(2)}\right)$, where $v^{\left(s_{t}\right)}=(0,0)$ and $A^{\left(s_{t}\right)}=(0.3,0.9)$. Notice that the total replication is 1000.

The first column shows the possible values that $\sigma^{\left(s_{t}\right)}$ can take. Notice that in the regime-specific case, $\sigma^{\left(s_{t}\right)}$ is set to 0.5 if $s_{t}=$ regime 1 and 1 if $s_{t}=$ regime 2. The second column shows the relevant information criterion being considered, while the third column indicates the number of regimes imposed on estimation. With sample size of 100, the fourth column depicts the frequency of selecting the correct number of variable (in this case, 1 variable) while the fifth column indicates the frequency of selecting the incorrect number of variables (in this case, 2 variables). Other columns show similar frequencies for different sample sizes.

\begin{tabular}{|c|c|c|c|c|c|c|c|c|c|c|}
\hline \multirow{2}{*}{ Sigma } & \multirow{2}{*}{$\begin{array}{l}\text { Information } \\
\text { criteria }\end{array}$} & \multirow{2}{*}{$\begin{array}{l}\text { No. of } \\
\text { regimes } \\
\text { imposed }\end{array}$} & \multicolumn{2}{|c|}{100 observations } & \multicolumn{2}{|c|}{200 observations } & \multicolumn{2}{|c|}{400 observations } & \multicolumn{2}{|c|}{500 observations } \\
\hline & & & 1 variable & 2 variables & 1 variable & 2 variables & 1 variable & 2 variables & 1 variable & 2 variables \\
\hline \multirow[t]{12}{*}{0.5} & \multirow[t]{3}{*}{$\mathrm{AIC}$} & 1 & 0 & 9 & 2 & 5 & 1 & 5 & 0 & 0 \\
\hline & & 2 & 663 & 294 & 720 & 232 & 770 & 193 & 822 & 154 \\
\hline & & 3 & 14 & 20 & 0 & 41 & 0 & 31 & 0 & 24 \\
\hline & \multirow[t]{3}{*}{$\mathrm{BIC}$} & 1 & 9 & 1 & 7 & 3 & 5 & 4 & 0 & 0 \\
\hline & & 2 & 811 & 175 & 963 & 27 & 976 & 15 & 992 & 8 \\
\hline & & 3 & 1 & 3 & 0 & 0 & 0 & 0 & 0 & 0 \\
\hline & \multirow[t]{3}{*}{ HQC } & 1 & 4 & 2 & 0 & 4 & 0 & 1 & 0 & 0 \\
\hline & & 2 & 787 & 162 & 899 & 94 & 918 & 77 & 936 & 63 \\
\hline & & 3 & 6 & 39 & 0 & 3 & 0 & 4 & 0 & 1 \\
\hline & \multirow[t]{3}{*}{ MSC } & 1 & 2 & 4 & 0 & 5 & 0 & 3 & 0 & 0 \\
\hline & & 2 & 771 & 110 & 812 & 121 & 920 & 44 & 949 & 47 \\
\hline & & 3 & 20 & 93 & 60 & 2 & 30 & 3 & 0 & 4 \\
\hline \multirow[t]{12}{*}{1.0} & \multirow[t]{3}{*}{ AIC } & 1 & 2 & 20 & 9 & 20 & 3 & 16 & 1 & 3 \\
\hline & & 2 & 651 & 256 & 716 & 220 & 760 & 200 & 775 & 187 \\
\hline & & 3 & 1 & 70 & 6 & 29 & 1 & 20 & 4 & 30 \\
\hline & \multirow[t]{3}{*}{ BIC } & 1 & 6 & 2 & 8 & 0 & 1 & 0 & 0 & 0 \\
\hline & & 2 & 802 & 190 & 940 & 52 & 968 & 31 & 978 & 22 \\
\hline & & 3 & 0 & 0 & 0 & 0 & 0 & 0 & 0 & 0 \\
\hline & \multirow[t]{3}{*}{ HQC } & 1 & 7 & 9 & 8 & 5 & 8 & 2 & 7 & 2 \\
\hline & & 2 & 739 & 238 & 885 & 101 & 900 & 90 & 920 & 67 \\
\hline & & 3 & 1 & 6 & 0 & 1 & 0 & 0 & 1 & 3 \\
\hline & \multirow[t]{3}{*}{ MSC } & 1 & 1 & 17 & 4 & 4 & 0 & 0 & 0 & 0 \\
\hline & & 2 & 762 & 150 & 806 & 146 & 909 & 69 & 939 & 53 \\
\hline & & 3 & 10 & 60 & 15 & 25 & 10 & 12 & 2 & 6 \\
\hline \multirow{12}{*}{$\begin{array}{l}\text { Regime- } \\
\text { specific }\end{array}$} & \multirow[t]{3}{*}{$\mathrm{AIC}$} & 1 & 3 & 15 & 9 & 12 & 5 & 9 & 0 & 0 \\
\hline & & 2 & 780 & 160 & 807 & 130 & 825 & 130 & 849 & 88 \\
\hline & & 3 & 2 & 40 & 1 & 41 & 18 & 13 & 10 & 53 \\
\hline & \multirow[t]{3}{*}{$\mathrm{BIC}$} & 1 & 4 & 1 & 5 & 0 & 1 & 0 & 1 & 0 \\
\hline & & 2 & 885 & 110 & 901 & 94 & 910 & 85 & 951 & 48 \\
\hline & & 3 & 0 & 0 & 0 & 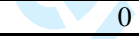 & 0 & 4 & 0 & 0 \\
\hline & \multirow[t]{3}{*}{ HQC } & 1 & 9 & 1 & 3 & 7 & 0 & 5 & 0 & 0 \\
\hline & & 2 & 800 & 190 & 805 & 181 & 810 & 153 & 893 & 97 \\
\hline & & 3 & 0 & 0 & 2 & 2 & 2 & 30 & 0 & 10 \\
\hline & \multirow[t]{3}{*}{ MSC } & 1 & 6 & 4 & 6 & 2 & 0 & 1 & 0 & 2 \\
\hline & & 2 & 860 & 20 & 901 & 47 & 910 & 72 & 915 & 80 \\
\hline & & 3 & 19 & 91 & 13 & 31 & 3 & 14 & 1 & 2 \\
\hline
\end{tabular}


1

4

5

6

Table 7: Frequency of selection of a MS(2)-AR(1) autoregressive model - Change in autoregressive coefficient The true data generating process is the MS-AR model with two regimes and one lag, as follows:

$$
y_{t}=v^{\left(s_{t}\right)}+A^{\left(s_{t}\right)} y_{t-1}+\sigma^{\left(s_{t}\right)} e_{t}
$$

The initial probabilities are set to 0.4 and 0.6 with the transition probabilities as $p_{11}=0.6 ; p_{22}=0.4$. The true regression coefficients are $v^{\left(s_{t}\right)}=\left(v^{(1)}, v^{(2)}\right)$ and $A^{\left(s_{t}\right)}=\left(A^{(1)}, A^{(2)}\right)$, where $v^{\left(s_{t}\right)}=(0,0)^{\prime}$ and $A^{\left(s_{t}\right)}=(0.3,0.9)^{\prime}$. Notice that the total replication is 1000 .

The first column shows the possible values that $\sigma^{\left(s_{t}\right)}$ can take. Notice that in the regime-specific case, $\sigma^{\left(s_{t}\right)}$ is set to 0.5 if $s_{t}=$ regime 1 and 1 if $s_{t}=$ regime 2. The second column shows the relevant information criterion being considered, while the third column indicates the number of regimes imposed on estimation. With sample size of 100, the fourth column depicts the frequency of selecting the correct lag length (in this case, 1 lag) while the fifth and sixth columns indicate the frequency of selecting the incorrect lag lengths (in this case, 2 and 3 lags). Other columns show similar frequencies for different sample sizes.

\begin{tabular}{|c|c|c|c|c|c|c|c|c|c|c|c|c|c|c|}
\hline \multirow{2}{*}{ Sigma } & \multirow{2}{*}{$\begin{array}{c}\text { Information } \\
\text { Criteria }\end{array}$} & \multirow{2}{*}{$\begin{array}{c}\text { No. of } \\
\text { regimes } \\
\text { imposed }\end{array}$} & \multicolumn{3}{|c|}{100 observations } & \multicolumn{3}{|c|}{200 observations } & \multicolumn{3}{|c|}{400 observations } & \multicolumn{3}{|c|}{500 observations } \\
\hline & & & $\mathrm{AR}(1)$ & $\mathrm{AR}(2)$ & $\mathrm{AR}(3)$ & $\mathrm{AR}(1)$ & $\mathrm{AR}(2)$ & $\mathrm{AR}(3)$ & $\mathrm{AR}(1)$ & $\mathrm{AR}(2)$ & $\mathrm{AR}(3)$ & $\mathrm{AR}(1)$ & $\operatorname{AR}(2)$ & $\mathrm{AR}(3)$ \\
\hline \multirow[t]{12}{*}{0.5} & \multirow[t]{3}{*}{ AIC } & 1 & 38 & 64 & 83 & 4 & 77 & 72 & 33 & 42 & 73 & 46 & 48 & 46 \\
\hline & & 2 & 696 & 24 & 80 & 712 & 35 & 83 & 735 & 52 & 60 & 740 & 59 & 47 \\
\hline & & 3 & 5 & 2 & 8 & 7 & 5 & 5 & 3 & 1 & 1 & 4 & 5 & 5 \\
\hline & \multirow[t]{3}{*}{ BIC } & 1 & 56 & 24 & 14 & 19 & 1 & 0 & 21 & 0 & 0 & 17 & 0 & 0 \\
\hline & & 2 & 852 & 37 & 13 & 934 & 39 & 7 & 946 & 27 & 6 & 959 & 20 & 4 \\
\hline & & 3 & 1 & 1 & 2 & 0 & 0 & 0 & 0 & 0 & 0 & 0 & 0 & 0 \\
\hline & \multirow[t]{3}{*}{$\overline{\mathrm{HQC}}$} & 1 & 49 & 53 & 45 & 20 & 18 & 15 & 8 & 11 & 3 & 3 & 11 & 3 \\
\hline & & 2 & 733 & 45 & 37 & 842 & 51 & 45 & 877 & 66 & 35 & 893 & 53 & 36 \\
\hline & & 3 & 8 & 7 & 23 & 2 & 3 & 4 & 0 & 0 & 0 & 1 & 0 & 0 \\
\hline & \multirow[t]{3}{*}{ MSC } & 1 & 31 & 11 & 29 & 38 & 21 & 2 & 0 & 0 & 0 & 0 & 0 & 0 \\
\hline & & 2 & 772 & 85 & 63 & 838 & 32 & 49 & 876 & 36 & 88 & 914 & 42 & 43 \\
\hline & & 3 & 7 & 2 & 0 & 5 & 8 & 7 & 0 & 0 & 0 & 0 & 1 & 0 \\
\hline \multirow[t]{12}{*}{1.0} & \multirow[t]{3}{*}{ AIC } & 1 & 67 & 71 & 100 & 83 & 72 & 82 & 47 & 79 & 66 & 57 & 43 & 82 \\
\hline & & 2 & 600 & 56 & 84 & 634 & 14 & 101 & 651 & 22 & 127 & 706 & 50 & 50 \\
\hline & & 3 & 6 & 7 & 9 & 3 & 9 & 2 & 6 & 2 & 0 & 0 & 8 & 4 \\
\hline & \multirow[t]{3}{*}{ BIC } & 1 & 41 & 38 & 17 & 8 & 11 & 2 & 10 & 10 & 0 & 14 & 0 & 0 \\
\hline & & 2 & 844 & 47 & 10 & 929 & 32 & 18 & 942 & 28 & 10 & 948 & 33 & 5 \\
\hline & & 3 & 1 & 1 & 1 & 0 & 0 & 0 & 0 & 0 & 0 & 0 & 0 & 0 \\
\hline & \multirow[t]{3}{*}{ HQC } & 1 & 43 & 72 & 61 & 71 & 18 & 12 & 51 & 13 & 8 & 38 & 13 & 2 \\
\hline & & 2 & 694 & 64 & 53 & 762 & 86 & 45 & 806 & 80 & 40 & 859 & 52 & 35 \\
\hline & & 3 & 4 & 9 & 0 & 0 & 2 & 4 & 2 & 0 & 0 & 1 & 0 & 0 \\
\hline & \multirow[t]{3}{*}{ MSC } & 1 & 43 & 1 & 11 & 4 & 0 & 1 & 0 & 0 & 0 & 0 & 0 & 0 \\
\hline & & 2 & 644 & 185 & 103 & 716 & 190 & 72 & 803 & 155 & 42 & 907 & 38 & 53 \\
\hline & & 3 & 6 & 4 & 3 & 6 & 2 & 9 & 0 & 0 & 0 & 0 & 2 & 0 \\
\hline \multirow{12}{*}{$\begin{array}{l}\text { Regime- } \\
\text { specific }\end{array}$} & \multirow[t]{3}{*}{ AIC } & 1 & 69 & 39 & 31 & 47 & 10 & 14 & 9 & 2 & 3 & 4 & 0 & 0 \\
\hline & & 2 & 637 & 74 & 140 & 700 & 86 & 140 & 760 & 87 & 118 & 784 & 81 & 114 \\
\hline & & 3 & 1 & 1 & 8 & 1 & 2 & 0 & 5 & 8 & 8 & 2 & 9 & 6 \\
\hline & \multirow[t]{3}{*}{$\mathrm{BIC}$} & 1 & 40 & 29 & 15 & 23 & 17 & 3 & 30 & 8 & 0 & 2 & 8 & 0 \\
\hline & & 2 & 855 & 44 & 14 & 869 & 51 & 36 & 954 & 8 & 0 & 986 & 4 & 0 \\
\hline & & 3 & 1 & 0 & 2 & 1 & 0 & 0 & 0 & 0 & 0 & 0 & 0 & 0 \\
\hline & \multirow[t]{3}{*}{ HQC } & 1 & 7 & 61 & 26 & 34 & 30 & 24 & 39 & 3 & 1 & 12 & 2 & 0 \\
\hline & & 2 & 739 & 75 & 81 & 813 & 52 & 37 & 880 & 60 & 8 & 921 & 54 & 6 \\
\hline & & 3 & 5 & 5 & 1 & 4 & 2 & 4 & 4 & 4 & 1 & 2 & 3 & 0 \\
\hline & \multirow[t]{3}{*}{ MSC } & 1 & 77 & 7 & 24 & 10 & 1 & 2 & 0 & 0 & 1 & 0 & 0 & 0 \\
\hline & & 2 & 751 & 27 & 105 & 859 & 26 & 90 & 883 & 101 & 10 & 945 & 10 & 45 \\
\hline & & 3 & 3 & 5 & 1 & 5 & 6 & 1 & 0 & 0 & 5 & 0 & 0 & 0 \\
\hline
\end{tabular}


Table 8: Frequency of selection of a MS(2)-AR(1) autoregressive model - Change in intercept term

The true data generating process is the MS-AR model with two regimes and one lag, as follows:

$$
y_{t}=v^{\left(s_{t}\right)}+A^{\left(s_{t}\right)} y_{t-1}+\sigma^{\left(s_{t}\right)} e_{t}
$$

The initial probabilities are set to 0.4 and 0.6 with the transition probabilities as $p_{11}=0.6 ; p_{22}=0.4$. The true regression coefficients are $v^{\left(s_{t}\right)}=\left(v^{(1)}, v^{(2)}\right)$ and $A^{\left(s_{t}\right)}=\left(A^{(1)}, A^{(2)}\right)$, where $v^{\left(s_{t}\right)}=(0,1)^{\prime}$ and $A^{\left(s_{t}\right)}=(0.3,0.3)^{\prime}$. Notice that the total replication is 1000.

The first column shows the possible values that $\sigma^{\left(s_{t}\right)}$ can take. Notice that in the regime-specific case, $\sigma^{\left(s_{t}\right)}$ is set to 0.5 if $s_{t}=$ regime 1 and 1 if $s_{t}=$ regime 2. The second column shows the relevant information criterion being considered, while the third column indicates the number of regimes imposed on estimation. With sample size of 100 , the fourth column depicts the frequency of selecting the correct lag length (in this case, 1 lag) while the fifth and sixth columns indicate the frequency of selecting the incorrect lag lengths (in this case, 2 and 3 lags). Other columns show similar frequencies for different sample sizes.

\begin{tabular}{|c|c|c|c|c|c|c|c|c|c|c|c|c|c|c|}
\hline \multirow{2}{*}{ Sigma } & \multirow{2}{*}{$\begin{array}{c}\text { Information } \\
\text { Criteria }\end{array}$} & \multirow{2}{*}{$\begin{array}{c}\text { No. of } \\
\text { regimes } \\
\text { imposed }\end{array}$} & \multicolumn{3}{|c|}{100 observations } & \multicolumn{3}{|c|}{200 observations } & \multicolumn{3}{|c|}{400 observations } & \multicolumn{3}{|c|}{500 observations } \\
\hline & & & $\mathrm{AR}(1)$ & $\mathrm{AR}(2)$ & $\mathrm{AR}(3)$ & $\mathrm{AR}(1)$ & $\mathrm{AR}(2)$ & $\mathrm{AR}(3)$ & $\mathrm{AR}(1)$ & $\mathrm{AR}(2)$ & $\mathrm{AR}(3)$ & $\mathrm{AR}(1)$ & $\mathrm{AR}(2)$ & $\operatorname{AR}(3)$ \\
\hline \multirow[t]{12}{*}{0.5} & \multirow[t]{3}{*}{$\overline{\mathrm{AIC}}$} & 1 & 9 & 61 & 45 & 3 & 55 & 43 & 3 & 42 & 41 & 3 & 31 & 41 \\
\hline & & 2 & 677 & 73 & 128 & 680 & 94 & 105 & 705 & 106 & 88 & 756 & 39 & 127 \\
\hline & & 3 & 6 & 1 & 0 & 9 & 4 & 7 & 9 & 0 & 6 & 0 & 2 & 1 \\
\hline & \multirow[t]{3}{*}{$\overline{B I C}$} & 1 & 35 & 10 & 0 & 11 & 23 & 0 & 22 & 10 & 0 & 39 & 0 & $\overline{0}$ \\
\hline & & 2 & 900 & 44 & 11 & 924 & 37 & 5 & 935 & 25 & 8 & 945 & 15 & 1 \\
\hline & & 3 & 0 & 0 & 0 & 0 & 0 & 0 & 0 & 0 & 0 & 0 & 0 & 0 \\
\hline & \multirow[t]{3}{*}{ HQC } & 1 & 86 & 21 & 29 & 58 & 17 & 2 & 21 & 1 & 11 & 6 & 20 & 5 \\
\hline & & 2 & 720 & 89 & 36 & 802 & 94 & 23 & 853 & 72 & 41 & 885 & 57 & 27 \\
\hline & & 3 & 4 & 8 & 7 & 0 & 2 & 2 & 0 & 1 & 0 & 0 & 0 & $\overline{0}$ \\
\hline & \multirow[t]{3}{*}{ MSC } & 1 & 8 & 3 & 10 & 1 & 0 & 0 & 0 & 0 & 0 & 0 & 0 & 0 \\
\hline & & 2 & 723 & 132 & 114 & 792 & 100 & 103 & 794 & 109 & 96 & 845 & 132 & 23 \\
\hline & & 3 & 3 & 1 & 6 & 1 & 0 & 3 & 0 & 1 & 0 & 0 & 0 & 0 \\
\hline \multirow[t]{12}{*}{1.0} & \multirow[t]{3}{*}{ AIC } & 1 & 37 & 76 & 57 & 34 & 77 & 69 & 0 & 0 & 0 & 60 & 15 & 8 \\
\hline & & 2 & 536 & 141 & 139 & 544 & 148 & 119 & 634 & 116 & 230 & 669 & 61 & 170 \\
\hline & & 3 & 9 & 4 & 1 & 0 & 1 & 8 & 5 & 9 & 6 & 0 & 8 & $\overline{9}$ \\
\hline & \multirow[t]{3}{*}{ BIC } & 1 & 39 & 3 & 4 & 7 & 10 & 9 & 0 & 0 & 0 & 0 & 0 & $\overline{0}$ \\
\hline & & 2 & 884 & 55 & 15 & 912 & 47 & 14 & 920 & 55 & 25 & 936 & 25 & 39 \\
\hline & & 3 & 0 & 0 & 0 & 1 & 0 & 0 & 0 & 0 & 0 & 0 & 0 & 0 \\
\hline & \multirow[t]{3}{*}{ HQC } & 1 & 65 & 14 & 29 & 9 & 38 & 30 & 10 & 3 & 1 & 10 & 3 & 1 \\
\hline & & 2 & 734 & 89 & 58 & 765 & 84 & 60 & 866 & 78 & 42 & 886 & 78 & 22 \\
\hline & & 3 & 1 & 7 & 3 & 5 & 4 & 5 & 0 & 0 & 0 & 0 & 0 & 0 \\
\hline & \multirow[t]{3}{*}{ MSC } & 1 & 40 & 5 & 10 & 39 & 4 & 10 & 0 & 0 & 0 & 0 & 0 & 0 \\
\hline & & 2 & 672 & 126 & 127 & 722 & 113 & 90 & 858 & 112 & 30 & 888 & 110 & 1 \\
\hline & & 3 & 8 & 4 & 8 & 6 & 7 & 9 & 0 & 0 & 0 & 0 & 0 & 1 \\
\hline \multirow{12}{*}{$\begin{array}{l}\text { Regime- } \\
\text { specific }\end{array}$} & \multirow[t]{3}{*}{ AIC } & 1 & 38 & 8 & 7 & 0 & 1 & 2 & 0 & 0 & 0 & 46 & 21 & 27 \\
\hline & & 2 & 614 & 126 & 196 & 668 & 110 & 205 & 698 & 143 & 145 & 750 & 40 & 105 \\
\hline & & 3 & 1 & 4 & 6 & 6 & 1 & 7 & 8 & 3 & 3 & 0 & 7 & 4 \\
\hline & \multirow[t]{3}{*}{ BIC } & 1 & 89 & 37 & 11 & 51 & 15 & 3 & 4 & 0 & 0 & 0 & 0 & 0 \\
\hline & & 2 & 833 & 23 & 5 & 864 & 17 & 50 & 941 & 55 & 0 & 964 & 34 & 2 \\
\hline & & 3 & 1 & 1 & 0 & 0 & 0 & 0 & 0 & 0 & 0 & 0 & 0 & 0 \\
\hline & \multirow[t]{3}{*}{$\mathrm{HQC}$} & 1 & 14 & 32 & 14 & 39 & 3 & 6 & 0 & 0 & 0 & 3 & 2 & $\overline{0}$ \\
\hline & & 2 & 737 & 102 & 85 & 805 & 104 & 25 & 821 & 158 & 16 & 865 & 104 & 26 \\
\hline & & 3 & 3 & 9 & 4 & 8 & 2 & 8 & 5 & 0 & 0 & 0 & 0 & 0 \\
\hline & \multirow[t]{3}{*}{ MSC } & 1 & 24 & 2 & 11 & 6 & 0 & 0 & 0 & 0 & 0 & 0 & 0 & $\overline{0}$ \\
\hline & & 2 & 706 & 110 & 138 & 745 & 153 & 78 & 790 & 150 & 60 & 901 & 10 & 89 \\
\hline & & 3 & 6 & 0 & 3 & 3 & 6 & 9 & 0 & 0 & 0 & 0 & 0 & $\overline{0}$ \\
\hline
\end{tabular}


Table 9: Frequency of selection of a $\operatorname{MS}(2)-\operatorname{AR}(1)$ autoregressive model - Changes in intercept term and autoregressive coefficient

The true data generating process is the MS-AR model with two regimes and one lag, as follows:

$$
y_{t}=v^{\left(s_{t}\right)}+A^{\left(s_{t}\right)} y_{t-1}+\sigma^{\left(s_{t}\right)} e_{t}
$$

The initial probabilities are set to 0.4 and 0.6 with the transition probabilities as $p_{11}=0.6 ; p_{22}=0.4$. The true regression coefficients are $v^{\left(s_{t}\right)}=\left(v^{(1)}, v^{(2)}\right)$ and $A^{\left(s_{t}\right)}=\left(A^{(1)}, A^{(2)}\right)$, where $v^{\left(s_{t}\right)}=(0,1)^{\prime}$ and $A^{\left(s_{t}\right)}=(0.3,0.9)^{\prime}$. Notice that the total replication is 1000 .

The first column shows the possible values that $\sigma^{\left(s_{t}\right)}$ can take. Notice that in the regime-specific case, $\sigma^{\left(s_{t}\right)}$ is set to 0.5 if $s_{t}=$ regime 1 and 1 if $s_{t}=$ regime 2 . The second column shows the relevant information criterion being considered, while the third column indicates the number of regimes imposed on estimation. With sample size of 100, the fourth column depicts the frequency of selecting the correct lag length (in this case, 1 lag) while the fifth and sixth columns indicate the frequency of selecting the incorrect lag lengths (in this case, 2 and 3 lags). Other columns show similar frequencies for different sample sizes.

\begin{tabular}{|c|c|c|c|c|c|c|c|c|c|c|c|c|c|c|}
\hline \multirow{2}{*}{ Sigma } & \multirow{2}{*}{$\begin{array}{c}\text { Information } \\
\text { Criteria }\end{array}$} & \multirow{2}{*}{$\begin{array}{l}\text { No. of } \\
\text { regimes } \\
\text { imposed }\end{array}$} & \multicolumn{3}{|c|}{100 observations } & \multicolumn{3}{|c|}{200 observations } & \multicolumn{3}{|c|}{400 observations } & \multicolumn{3}{|c|}{500 observations } \\
\hline & & & $\mathrm{AR}(1)$ & $\mathrm{AR}(2)$ & $\mathrm{AR}(3)$ & $\mathrm{AR}(1)$ & $\mathrm{AR}(2)$ & $\mathrm{AR}(3)$ & $\mathrm{AR}(1)$ & $\mathrm{AR}(2)$ & $\mathrm{AR}(3)$ & $\mathrm{AR}(1)$ & $\mathrm{AR}(2)$ & $\operatorname{AR}(3)$ \\
\hline \multirow[t]{12}{*}{0.5} & \multirow[t]{3}{*}{ AIC } & 1 & 2 & 0 & 0 & 7 & 2 & 0 & 0 & 0 & 0 & 0 & 0 & 69 \\
\hline & & 2 & 614 & 217 & 155 & 653 & 174 & 151 & 694 & 157 & 130 & 725 & 141 & 51 \\
\hline & & 3 & 5 & 2 & 5 & 9 & 2 & 2 & 8 & 9 & 2 & 8 & 6 & 0 \\
\hline & \multirow[t]{3}{*}{$\mathrm{BIC}$} & 1 & 111 & 6 & 4 & 44 & 0 & 0 & 0 & 0 & 0 & 0 & 0 & 1 \\
\hline & & 2 & 835 & 37 & 6 & 942 & 11 & 1 & 988 & 12 & 0 & 994 & 5 & 0 \\
\hline & & 3 & 1 & 0 & 0 & 2 & 0 & 0 & 0 & 0 & 0 & 0 & 0 & 0 \\
\hline & \multirow[t]{3}{*}{$\overline{\mathrm{HQC}}$} & 1 & 18 & 4 & 3 & 15 & 2 & 0 & 0 & 0 & 0 & 0 & 0 & 0 \\
\hline & & 2 & 799 & 103 & 61 & 893 & 63 & 16 & 947 & 42 & 7 & 945 & 44 & 8 \\
\hline & & 3 & 3 & 4 & 5 & 3 & 5 & 3 & 2 & 1 & 1 & 3 & 0 & 0 \\
\hline & \multirow[t]{3}{*}{ MSC } & 1 & 10 & 0 & 1 & 8 & 0 & 0 & 0 & 0 & 0 & 0 & 0 & 0 \\
\hline & & 2 & 759 & 165 & 61 & 845 & 120 & 8 & 831 & 97 & 70 & 909 & 41 & 50 \\
\hline & & 3 & 3 & 0 & 1 & 1 & 2 & 16 & 0 & 1 & 1 & 0 & 0 & 0 \\
\hline \multirow[t]{12}{*}{1.0} & \multirow[t]{3}{*}{ AIC } & 1 & 95 & 17 & 13 & 20 & 5 & 5 & 27 & 122 & 68 & 1 & 1 & 0 \\
\hline & & 2 & 572 & 129 & 154 & 655 & 207 & 95 & 676 & 45 & 60 & 712 & 169 & 105 \\
\hline & & 3 & 7 & 5 & 8 & 5 & 0 & 8 & 1 & 1 & 0 & 2 & 3 & 7 \\
\hline & \multirow[t]{3}{*}{ BIC } & 1 & 95 & 37 & 18 & 116 & 18 & 15 & 94 & 12 & 0 & 32 & 0 & 0 \\
\hline & & 2 & 821 & 19 & 8 & 845 & 6 & 0 & 879 & 14 & 1 & 960 & 8 & 0 \\
\hline & & 3 & 0 & 1 & 1 & 0 & 0 & 0 & 0 & 0 & 0 & 0 & 0 & 0 \\
\hline & \multirow[t]{3}{*}{ HQC } & 1 & 48 & 43 & 19 & 43 & 20 & 9 & 10 & 1 & 0 & 2 & 0 & 0 \\
\hline & & 2 & 719 & 85 & 72 & 821 & 73 & 20 & 909 & 57 & 13 & 923 & 54 & 15 \\
\hline & & 3 & 1 & 8 & 5 & 9 & 4 & 1 & 8 & 1 & 1 & 5 & 1 & 0 \\
\hline & \multirow[t]{3}{*}{ MSC } & 1 & 18 & 4 & 4 & 12 & 0 & 0 & 10 & 0 & 0 & 0 & 0 & 0 \\
\hline & & 2 & 812 & 51 & 99 & 870 & 51 & 59 & 888 & 50 & 50 & 898 & 51 & 51 \\
\hline & & 3 & 3 & 5 & 4 & 0 & 3 & 5 & 1 & 1 & 0 & 0 & 0 & 0 \\
\hline \multirow{12}{*}{$\begin{array}{l}\text { Regime- } \\
\text { specific }\end{array}$} & \multirow[t]{3}{*}{ AIC } & 1 & 2 & 1 & 0 & 0 & 0 & 0 & 0 & 0 & 0 & 0 & 0 & 0 \\
\hline & & 2 & 609 & 112 & 260 & 623 & 189 & 168 & 682 & 171 & 130 & 718 & 147 & 125 \\
\hline & & 3 & 6 & 6 & 4 & 9 & 9 & 2 & 9 & 2 & 6 & 2 & 8 & 0 \\
\hline & \multirow[t]{3}{*}{ BIC } & 1 & 72 & 7 & 2 & 20 & 0 & 0 & 10 & 0 & 0 & 0 & 0 & 0 \\
\hline & & 2 & 875 & 35 & 5 & 958 & 18 & 3 & 972 & 17 & 1 & 993 & 7 & 0 \\
\hline & & 3 & 2 & 1 & 1 & 1 & 0 & 0 & 0 & 0 & 0 & 0 & 0 & 0 \\
\hline & \multirow[t]{3}{*}{ HQC } & 1 & 15 & 2 & 1 & 0 & 0 & 0 & 0 & 0 & 0 & 0 & 0 & 0 \\
\hline & & 2 & 790 & 113 & 65 & 906 & 62 & 21 & 936 & 45 & 11 & 940 & 50 & 7 \\
\hline & & 3 & 3 & 9 & 2 & 4 & 3 & 4 & 8 & 0 & 0 & 2 & 1 & 0 \\
\hline & \multirow[t]{3}{*}{ MSC } & 1 & 29 & 2 & 4 & 10 & 0 & 0 & 0 & 0 & 0 & 0 & 0 & 0 \\
\hline & & 2 & 732 & 129 & 86 & 802 & 101 & 75 & 902 & 20 & 77 & 940 & 10 & 50 \\
\hline & & 3 & 1 & 9 & 8 & 2 & 3 & 7 & 1 & 0 & 0 & 0 & 0 & 0 \\
\hline
\end{tabular}


Table 10: Frequency of selection of a MS(2)-AR(1) autoregressive model - Change in transition probabilities

The true data generating process is the MS-AR model with two regimes and one lag, as follows:

$$
y_{t}=v^{\left(s_{t}\right)}+A^{\left(s_{t}\right)} y_{t-1}+\sigma^{\left(s_{t}\right)} e_{t}
$$

The initial probabilities are set to 0.4 and 0.6 with the transition probabilities as $p_{11}=0.9 ; p_{22}=0.1$. The true regression coefficients are $v^{\left(s_{t}\right)}=\left(v^{(1)}, v^{(2)}\right)$ and $A^{\left(s_{t}\right)}=\left(A^{(1)}, A^{(2)}\right)$, where $v^{\left(s_{t}\right)}=(0,0)^{\prime}$ and $A^{\left(s_{t}\right)}=(0.3,0.9)^{\prime}$. Notice that the total replication is 1000.

The first column shows the possible values that $\sigma^{\left(s_{t}\right)}$ can take. Notice that in the regime-specific case, $\sigma^{\left(s_{t}\right)}$ is set to 0.5 if $s_{t}=$ regime 1 and 1 if $s_{t}=$ regime 2 . The second column shows the relevant information criterion being considered, while the third column indicates the number of regimes imposed on estimation. With sample size of 100, the fourth column depicts the frequency of selecting the correct lag length (in this case, 1 lag) while the fifth and sixth columns indicate the frequency of selecting the incorrect lag lengths (in this case, 2 and 3 lags). Other columns show similar frequencies for different sample sizes.

\begin{tabular}{|c|c|c|c|c|c|c|c|c|c|c|c|c|c|c|}
\hline \multirow{2}{*}{ Sigma } & \multirow{2}{*}{$\begin{array}{c}\text { Information } \\
\text { Criteria }\end{array}$} & \multirow{2}{*}{$\begin{array}{c}\text { No. of } \\
\text { regimes } \\
\text { imposed }\end{array}$} & \multicolumn{3}{|c|}{100 observations } & \multicolumn{3}{|c|}{200 observations } & \multicolumn{3}{|c|}{400 observations } & \multicolumn{3}{|c|}{500 observations } \\
\hline & & & $\mathrm{AR}(1)$ & $\mathrm{AR}(2)$ & $\mathrm{AR}(3)$ & $\mathrm{AR}(1)$ & $\mathrm{AR}(2)$ & $\mathrm{AR}(3)$ & $\operatorname{AR}(1)$ & $\mathrm{AR}(2)$ & $\mathrm{AR}(3)$ & $\mathrm{AR}(1)$ & $\mathrm{AR}(2)$ & $\operatorname{AR}(3)$ \\
\hline \multirow[t]{12}{*}{0.5} & \multirow[t]{3}{*}{$\overline{\mathrm{AIC}}$} & 1 & 19 & 64 & 94 & 43 & 61 & 72 & 77 & 40 & 42 & 73 & 43 & 29 \\
\hline & & 2 & 674 & 52 & 93 & 705 & 51 & 60 & 761 & 35 & 35 & 790 & 43 & 10 \\
\hline & & 3 & 0 & 1 & 3 & 0 & 7 & 1 & 4 & 0 & 6 & 1 & 4 & 7 \\
\hline & \multirow[t]{3}{*}{$\overline{B I C}$} & 1 & 56 & 0 & 5 & 6 & 1 & 8 & 1 & 0 & 0 & 0 & 0 & 0 \\
\hline & & 2 & 888 & 43 & 8 & 941 & 38 & 6 & 959 & 36 & 4 & 963 & 31 & 6 \\
\hline & & 3 & 0 & 0 & 0 & 0 & 0 & 0 & 0 & 0 & 0 & 0 & 0 & 0 \\
\hline & \multirow[t]{3}{*}{ HQC } & 1 & 40 & 20 & 39 & 27 & 8 & 6 & 15 & 2 & 1 & 8 & 3 & 1 \\
\hline & & 2 & 758 & 89 & 47 & 842 & 81 & 31 & 868 & 72 & 41 & 878 & 78 & 32 \\
\hline & & 3 & 2 & 5 & 0 & 1 & 3 & 1 & 1 & 0 & 0 & 0 & 0 & $\overline{0}$ \\
\hline & \multirow[t]{3}{*}{ MSC } & 1 & 53 & 8 & 8 & 6 & 0 & 1 & 1 & 0 & 0 & 0 & 0 & 0 \\
\hline & & 2 & 848 & 20 & 56 & 886 & 31 & 52 & 890 & 54 & 52 & 921 & 44 & 35 \\
\hline & & 3 & 2 & 2 & 3 & 2 & 8 & 14 & 0 & 0 & 3 & 0 & 0 & 0 \\
\hline \multirow[t]{12}{*}{1.0} & \multirow[t]{3}{*}{ AIC } & 1 & 16 & 70 & 76 & 69 & 80 & 80 & 62 & 46 & 47 & 65 & 29 & 37 \\
\hline & & 2 & 607 & 44 & 179 & 640 & 103 & 18 & 663 & 47 & 125 & 691 & 60 & 94 \\
\hline & & 3 & 2 & 4 & 2 & 0 & 4 & 6 & 0 & 3 & 7 & 7 & 8 & $\overline{9}$ \\
\hline & \multirow[t]{3}{*}{$\overline{B I C}$} & 1 & 46 & 5 & 2 & 15 & 15 & 4 & $\overline{0}$ & 1 & 0 & 2 & 0 & $\overline{0}$ \\
\hline & & 2 & 873 & 65 & 9 & 925 & 37 & 4 & 937 & 29 & 33 & 959 & 25 & 14 \\
\hline & & 3 & 0 & 0 & 0 & 0 & 0 & 0 & 0 & 0 & 0 & 0 & 0 & $\overline{0}$ \\
\hline & \multirow[t]{3}{*}{ HQC } & 1 & 81 & 20 & 21 & 53 & 52 & 29 & 1 & 1 & 0 & 14 & 1 & 0 \\
\hline & & 2 & 718 & 95 & 54 & 762 & 73 & 22 & 855 & 90 & 45 & 869 & 87 & 29 \\
\hline & & 3 & 3 & 5 & 3 & 2 & 1 & 6 & 4 & 4 & 0 & 0 & 0 & 0 \\
\hline & \multirow[t]{3}{*}{ MSC } & 1 & 47 & 1 & 16 & 7 & 2 & 2 & 0 & 0 & 0 & 0 & 0 & 0 \\
\hline & & 2 & 754 & 162 & 7 & 814 & 102 & 55 & 858 & 77 & 64 & 911 & 80 & 9 \\
\hline & & 3 & 2 & 3 & 8 & 2 & 7 & 9 & 0 & 1 & 0 & 0 & 0 & 0 \\
\hline \multirow{12}{*}{$\begin{array}{l}\text { Regime- } \\
\text { specific }\end{array}$} & \multirow[t]{3}{*}{ AIC } & 1 & 17 & 43 & 52 & 18 & 50 & 31 & 30 & 20 & 21 & 8 & 25 & 10 \\
\hline & & 2 & 669 & 70 & 131 & 703 & 64 & 125 & 766 & 74 & 77 & 788 & 65 & 89 \\
\hline & & 3 & 8 & 6 & 4 & 5 & 0 & 4 & 3 & 4 & 5 & 9 & 0 & 6 \\
\hline & \multirow[t]{3}{*}{ BIC } & 1 & 26 & 26 & 27 & 34 & 19 & 8 & 10 & 5 & 7 & 1 & 8 & 5 \\
\hline & & 2 & 850 & 52 & 12 & 887 & 33 & 15 & 954 & 20 & 4 & 963 & 20 & 3 \\
\hline & & 3 & 3 & 1 & 3 & 0 & 1 & 3 & 0 & 0 & 0 & 0 & 0 & 0 \\
\hline & \multirow[t]{3}{*}{$\mathrm{HQC}$} & 1 & 9 & 58 & 71 & 31 & 40 & 48 & 20 & 38 & 14 & 8 & 30 & $\overline{9}$ \\
\hline & & 2 & 733 & 53 & 64 & $\begin{array}{l}787 \\
\end{array}$ & 50 & 29 & 842 & 42 & 26 & 870 & 54 & 21 \\
\hline & & 3 & 2 & 9 & 1 & 9 & 5 & 1 & 5 & 4 & 9 & 3 & 2 & 3 \\
\hline & \multirow[t]{3}{*}{ MSC } & 1 & 82 & 17 & 26 & 39 & 4 & 13 & 14 & 2 & 1 & 4 & 1 & $\overline{0}$ \\
\hline & & 2 & 783 & 26 & 52 & 819 & 30 & 86 & 896 & 54 & 22 & 939 & 44 & 7 \\
\hline & & 3 & 6 & 4 & 4 & 2 & 1 & 6 & 3 & 6 & 2 & 1 & 4 & $\overline{0}$ \\
\hline
\end{tabular}


1

Table 11: Frequency of selection of a $\operatorname{MS}(2)-\operatorname{AR}(1)$ autoregressive model - Change in initial probabilities The true data generating process is the MS-AR model with two regimes and one lag, as follows:

$$
y_{t}=v^{\left(s_{t}\right)}+A^{\left(s_{t}\right)} y_{t-1}+\sigma^{\left(s_{t}\right)} e_{t} .
$$

The initial probabilities are set to 0.1 and 0.9 with the transition probabilities as $p_{11}=0.6 ; p_{22}=0.4$. The true regression coefficients are $v^{\left(s_{t}\right)}=\left(v^{(1)}, v^{(2)}\right)$ and $A^{\left(s_{t}\right)}=\left(A^{(1)}, A^{(2)}\right)$, where $v^{\left(s_{t}\right)}=(0,0)^{\prime}$ and $A^{\left(s_{t}\right)}=(0.3,0.9)^{\prime}$. Notice that the total replication is 1000 .

The first column shows the possible values that $\sigma^{\left(s_{t}\right)}$ can take. Notice that in the regime-specific case, $\sigma^{\left(s_{t}\right)}$ is set to 0.5 if $s_{t}=$ regime 1 and 1 if $s_{t}=$ regime 2 . The second column shows the relevant information criterion being considered, while the third column indicates the number of regimes imposed on estimation. With sample size of 100, the fourth column depicts the frequency of selecting the correct lag length (in this case, 1 lag) while the fifth and sixth columns indicate the frequency of selecting the incorrect lag lengths (in this case, 2 and 3 lags). Other columns show similar frequencies for different sample sizes.

\begin{tabular}{|c|c|c|c|c|c|c|c|c|c|c|c|c|c|c|}
\hline \multirow{2}{*}{ Sigma } & \multirow{2}{*}{$\begin{array}{c}\text { Information } \\
\text { Criteria }\end{array}$} & \multirow{2}{*}{$\begin{array}{c}\text { No. of } \\
\text { regimes } \\
\text { imposed }\end{array}$} & \multicolumn{3}{|c|}{100 observations } & \multicolumn{3}{|c|}{200 observations } & \multicolumn{3}{|c|}{400 observations } & \multicolumn{3}{|c|}{500 observations } \\
\hline & & & $\mathrm{AR}(1)$ & $\mathrm{AR}(2)$ & $\mathrm{AR}(3)$ & $\operatorname{AR}(1)$ & $\mathrm{AR}(2)$ & $\mathrm{AR}(3)$ & $\mathrm{AR}(1)$ & $\mathrm{AR}(2)$ & $\operatorname{AR}(3)$ & $\mathrm{AR}(1)$ & $\operatorname{AR}(2)$ & $\operatorname{AR}(3)$ \\
\hline \multirow[t]{12}{*}{0.5} & \multirow[t]{3}{*}{ AIC } & 1 & 95 & 61 & 40 & 74 & 98 & 49 & 27 & 94 & 58 & 48 & 40 & 50 \\
\hline & & 2 & 680 & 41 & 62 & 691 & 21 & 57 & 770 & 6 & 26 & 807 & 16 & 32 \\
\hline & & 3 & 7 & 8 & 6 & 2 & 3 & 5 & 9 & 8 & 2 & 2 & 3 & 2 \\
\hline & \multirow[t]{3}{*}{$\mathrm{BIC}$} & 1 & 80 & 4 & 1 & 15 & 0 & 1 & 19 & 0 & 0 & 10 & 0 & 0 \\
\hline & & 2 & 915 & 0 & 0 & 920 & 52 & 12 & 930 & 37 & 14 & 946 & 38 & 6 \\
\hline & & 3 & 0 & 0 & 0 & 0 & 0 & 0 & 0 & 0 & 0 & 0 & 0 & 0 \\
\hline & \multirow[t]{3}{*}{$\overline{\mathrm{HQC}}$} & 1 & 56 & 36 & 38 & 75 & 15 & 12 & 4 & 13 & 6 & 7 & 12 & 1 \\
\hline & & 2 & 703 & 95 & 52 & 758 & 92 & 39 & 862 & 84 & 28 & 873 & 77 & 30 \\
\hline & & 3 & 5 & 8 & 7 & 2 & 3 & 4 & 3 & 0 & 0 & 0 & 0 & 0 \\
\hline & \multirow[t]{3}{*}{ MSC } & 1 & 43 & 4 & 13 & 5 & 0 & 3 & 0 & 0 & 0 & 0 & 0 & 0 \\
\hline & & 2 & 713 & 150 & 69 & 754 & 163 & 70 & 828 & 150 & 20 & 842 & 145 & 13 \\
\hline & & 3 & 5 & 2 & 1 & 3 & 0 & 2 & 1 & 0 & 1 & 0 & 0 & 0 \\
\hline \multirow[t]{12}{*}{1.0} & \multirow[t]{3}{*}{ AIC } & 1 & 7 & 75 & 55 & 65 & 83 & 54 & 6 & 94 & 65 & 20 & 80 & 58 \\
\hline & & 2 & 610 & 115 & 119 & 637 & 36 & 116 & 680 & 8 & 127 & 799 & 12 & 8 \\
\hline & & 3 & 8 & 8 & 3 & 1 & 2 & 6 & 6 & 8 & 6 & 6 & 9 & 8 \\
\hline & \multirow[t]{3}{*}{ BIC } & 1 & 14 & 29 & 11 & 15 & 1 & 0 & 18 & 0 & 0 & 8 & 0 & 0 \\
\hline & & 2 & 879 & 44 & 20 & 929 & 43 & 12 & 948 & 30 & 4 & 960 & 28 & 4 \\
\hline & & 3 & 1 & 1 & 1 & 0 & 0 & 0 & 0 & 0 & 0 & 0 & 0 & 0 \\
\hline & \multirow[t]{3}{*}{ HQC } & 1 & 41 & 57 & 62 & 80 & 15 & 7 & 27 & 12 & 6 & 9 & 9 & 1 \\
\hline & & 2 & 695 & 79 & 58 & 769 & 85 & 36 & 839 & 86 & 30 & 878 & 73 & 29 \\
\hline & & 3 & 2 & 1 & 5 & 2 & 3 & 3 & 0 & 0 & 0 & 0 & 0 & 1 \\
\hline & \multirow[t]{3}{*}{ MSC } & 1 & 41 & 3 & 15 & 8 & 0 & 3 & 0 & 0 & 0 & 0 & 0 & 0 \\
\hline & & 2 & 734 & 136 & 55 & 807 & 77 & 91 & 891 & 58 & 51 & 902 & 57 & 41 \\
\hline & & 3 & 9 & 3 & 4 & 1 & 6 & 7 & 0 & 0 & 0 & 0 & 0 & 0 \\
\hline \multirow{12}{*}{$\begin{array}{l}\text { Regime- } \\
\text { specific }\end{array}$} & \multirow[t]{3}{*}{ AIC } & 1 & 17 & 41 & 41 & 50 & 13 & 9 & 3 & 1 & 4 & 0 & 0 & 0 \\
\hline & & 2 & 618 & 154 & 114 & 715 & 91 & 103 & 775 & 59 & 146 & 806 & 60 & 123 \\
\hline & & 3 & 2 & 6 & 7 & 3 & 7 & 9 & 8 & 4 & 0 & 4 & 0 & 7 \\
\hline & \multirow[t]{3}{*}{$\mathrm{BIC}$} & 1 & 26 & 25 & 15 & 58 & 9 & 4 & 12 & 13 & 0 & 0 & 3 & 1 \\
\hline & & 2 & 874 & 41 & 14 & 885 & 39 & 5 & 965 & 7 & 2 & 989 & 6 & 1 \\
\hline & & 3 & 1 & 2 & 2 & 0 & 0 & 0 & 0 & 1 & 0 & 0 & 0 & 0 \\
\hline & \multirow[t]{3}{*}{ HQC } & 1 & 40 & 43 & 33 & 53 & 31 & 10 & 51 & 6 & 3 & 6 & 2 & 1 \\
\hline & & 2 & 760 & 83 & 28 & 793 & 56 & 36 & 858 & 63 & 9 & 923 & 49 & 15 \\
\hline & & 3 & 7 & 0 & 6 & 7 & 9 & 5 & 4 & 3 & 3 & 4 & 0 & 0 \\
\hline & \multirow[t]{3}{*}{ MSC } & 1 & 70 & 12 & 25 & 8 & 2 & 1 & 0 & 0 & 0 & 0 & 0 & 0 \\
\hline & & 2 & 741 & 50 & 84 & 850 & 33 & 88 & 856 & 127 & 15 & 952 & 24 & 22 \\
\hline & & 3 & 8 & 5 & 5 & 7 & 2 & 9 & 0 & 0 & 2 & 0 & 1 & 1 \\
\hline
\end{tabular}


Table 12: Frequency of selection of a MS(2)-AR(1) autoregressive model - Persistence in $\left\{s_{t}\right\}$

The true data generating process is the MS-AR model with two regimes and one lag, as follows:

$$
y_{t}=v^{\left(s_{t}\right)}+A^{\left(s_{t}\right)} y_{t-1}+\sigma^{\left(s_{t}\right)} e_{t}
$$

The initial probabilities are set to 0.4 and 0.6 with the transition probabilities as $p_{11}=0.9 ; p_{22}=0.9$. The true regression coefficients are $v^{\left(s_{t}\right)}=\left(v^{(1)}, v^{(2)}\right)$ and $A^{\left(s_{t}\right)}=\left(A^{(1)}, A^{(2)}\right)$, where $v^{\left(s_{t}\right)}=(0,0)^{\prime}$ and $A^{\left(s_{t}\right)}=(0.3,0.9)^{\prime}$. Notice that the total replication is 1000.

The first column shows the possible values that $\sigma^{\left(s_{t}\right)}$ can take. Notice that in the regime-specific case, $\sigma^{\left(s_{t}\right)}$ is set to 0.5 if $s_{t}=$ regime 1 and 1 if $s_{t}=$ regime 2. The second column shows the relevant information criterion being considered, while the third column indicates the number of regimes imposed on estimation. With sample size of 100, the fourth column depicts the frequency of selecting the correct lag length (in this case, 1 lag) while the fifth and sixth columns indicate the frequency of selecting the incorrect lag lengths (in this case, 2 and 3 lags). Other columns show similar frequencies for different sample sizes.

\begin{tabular}{|c|c|c|c|c|c|c|c|c|c|c|c|c|c|c|}
\hline \multirow{2}{*}{ Sigma } & \multirow{2}{*}{$\begin{array}{c}\text { Information } \\
\text { Criteria }\end{array}$} & \multirow{2}{*}{$\begin{array}{c}\text { No. of } \\
\text { regimes } \\
\text { imposed }\end{array}$} & \multicolumn{3}{|c|}{100 observations } & \multicolumn{3}{|c|}{200 observations } & \multicolumn{3}{|c|}{400 observations } & \multicolumn{3}{|c|}{500 observations } \\
\hline & & & $\mathrm{AR}(1)$ & $\mathrm{AR}(2)$ & $\mathrm{AR}(3)$ & $\mathrm{AR}(1)$ & $\mathrm{AR}(2)$ & $\mathrm{AR}(3)$ & $\mathrm{AR}(1)$ & $\mathrm{AR}(2)$ & $\mathrm{AR}(3)$ & $\mathrm{AR}(1)$ & $\mathrm{AR}(2)$ & $\operatorname{AR}(3)$ \\
\hline \multirow[t]{12}{*}{0.5} & \multirow[t]{3}{*}{$\overline{\mathrm{AIC}}$} & 1 & 12 & 81 & 64 & 53 & 2 & 83 & 5 & 40 & 97 & 43 & 28 & 57 \\
\hline & & 2 & 643 & 45 & 147 & 693 & 59 & 104 & 700 & 56 & 81 & 728 & 60 & 64 \\
\hline & & 3 & 0 & 6 & 2 & 1 & 3 & 2 & 4 & 8 & 9 & 9 & 8 & 3 \\
\hline & \multirow[t]{3}{*}{$\overline{B I C}$} & 1 & 70 & 3 & 7 & 32 & 3 & 3 & 14 & 1 & 4 & 9 & 7 & 2 \\
\hline & & 2 & 838 & 67 & 14 & 911 & 51 & 0 & 951 & 30 & 0 & 961 & 21 & $\overline{0}$ \\
\hline & & 3 & 0 & 0 & 1 & 0 & 0 & 0 & 0 & 0 & 0 & 0 & 0 & 0 \\
\hline & \multirow[t]{3}{*}{ HQC } & 1 & 51 & 54 & 33 & 18 & 4 & 5 & 43 & 7 & 8 & 27 & 9 & 9 \\
\hline & & 2 & 760 & 41 & 50 & 823 & 109 & 35 & 832 & 73 & 34 & 861 & 73 & 21 \\
\hline & & 3 & 8 & 0 & 3 & 2 & 1 & 3 & 0 & 1 & 2 & 0 & 0 & $\overline{0}$ \\
\hline & \multirow[t]{3}{*}{ MSC } & 1 & 25 & 87 & 53 & 65 & 3 & 0 & 1 & 41 & 9 & 3 & 4 & 2 \\
\hline & & 2 & 758 & 45 & 14 & 810 & 40 & 73 & 851 & 60 & 35 & 890 & 20 & 80 \\
\hline & & 3 & 6 & 8 & 4 & 1 & 3 & 5 & 0 & 1 & 2 & 0 & 0 & 1 \\
\hline \multirow[t]{12}{*}{1.0} & \multirow[t]{3}{*}{ AIC } & 1 & 30 & 86 & 44 & 45 & 13 & 76 & 65 & 35 & 1 & 57 & 28 & 82 \\
\hline & & 2 & 575 & 116 & 136 & 601 & 98 & 148 & 668 & 46 & 169 & 684 & 49 & 85 \\
\hline & & 3 & 7 & 1 & 5 & 4 & 6 & 9 & 4 & 9 & 3 & 8 & 7 & $\overline{0}$ \\
\hline & \multirow[t]{3}{*}{$\overline{B I C}$} & 1 & 74 & 9 & 1 & 4 & 15 & 5 & 11 & 18 & 10 & 5 & 20 & 3 \\
\hline & & 2 & 840 & 52 & 23 & 935 & 41 & 0 & 941 & 20 & 0 & 951 & 20 & 1 \\
\hline & & 3 & 0 & 0 & 1 & 0 & 0 & 0 & 0 & 0 & 0 & 0 & 0 & $\overline{0}$ \\
\hline & \multirow[t]{3}{*}{ HQC } & 1 & 96 & 10 & 54 & 19 & 26 & 2 & 8 & 26 & 8 & 9 & 28 & 1 \\
\hline & & 2 & 759 & 25 & 36 & 803 & 108 & 37 & 827 & 90 & 41 & 859 & 72 & 31 \\
\hline & & 3 & 7 & 4 & 9 & 1 & 3 & 1 & 0 & 0 & 0 & 0 & 0 & 0 \\
\hline & \multirow[t]{3}{*}{ MSC } & 1 & 43 & 1 & 22 & 8 & 9 & 4 & 0 & 6 & 4 & 2 & 7 & 1 \\
\hline & & 2 & 751 & 58 & 114 & 794 & 60 & 111 & 810 & 80 & 100 & 850 & 130 & 10 \\
\hline & & 3 & 8 & 2 & 1 & 1 & 7 & 6 & 0 & 0 & 0 & 0 & 0 & 0 \\
\hline \multirow{12}{*}{$\begin{array}{l}\text { Regime- } \\
\text { specific }\end{array}$} & \multirow[t]{3}{*}{ AIC } & 1 & 33 & 70 & 53 & 54 & 59 & 41 & 11 & 28 & 24 & 99 & 38 & 26 \\
\hline & & 2 & 611 & 21 & 195 & 666 & 33 & 130 & 685 & 51 & 189 & 703 & 17 & 107 \\
\hline & & 3 & 6 & 8 & 3 & 4 & 6 & 7 & 3 & 4 & 5 & 8 & 2 & $\overline{0}$ \\
\hline & \multirow[t]{3}{*}{ BIC } & 1 & 69 & 47 & 16 & 68 & 34 & 5 & 91 & 8 & 0 & 41 & 3 & 4 \\
\hline & & 2 & 789 & 39 & 32 & 842 & 21 & 22 & 859 & 26 & 16 & 932 & 17 & 1 \\
\hline & & 3 & 0 & 2 & 6 & 1 & 1 & 6 & 0 & 0 & 0 & 1 & 1 & 0 \\
\hline & \multirow[t]{3}{*}{$\mathrm{HQC}$} & 1 & 3 & 76 & 36 & 21 & 50 & 19 & 54 & 37 & 24 & 67 & 26 & 13 \\
\hline & & 2 & 689 & 76 & 102 & 758 & 63 & 77 & 807 & 40 & 29 & 831 & 38 & 17 \\
\hline & & 3 & 6 & 5 & 7 & 1 & 5 & 6 & 3 & 2 & 4 & 4 & 2 & 2 \\
\hline & \multirow[t]{3}{*}{ MSC } & 1 & 50 & 75 & 17 & 90 & 6 & 15 & 6 & 3 & 5 & 5 & 2 & 6 \\
\hline & & 2 & 666 & 80 & 105 & 781 & 34 & 63 & 809 & 40 & 123 & 838 & 30 & 110 \\
\hline & & 3 & 1 & 2 & 4 & 2 & 5 & 4 & 2 & 7 & 5 & 1 & 2 & $\overline{6}$ \\
\hline
\end{tabular}

